NBER WORKING PAPER SERIES

\title{
DO RISK PREFERENCES CHANGE? EVIDENCE FROM PANEL DATA BEFORE AND AFTER THE GREAT EAST JAPAN EARTHQUAKE
}

\author{
Chie Hanaoka \\ Hitoshi Shigeoka \\ Yasutora Watanabe \\ Working Paper 21400 \\ http://www.nber.org/papers/w21400 \\ NATIONAL BUREAU OF ECONOMIC RESEARCH \\ 1050 Massachusetts Avenue \\ Cambridge, MA 02138 \\ July 2015
}

Previously circulated as "Do Risk Preferences Change? Evidence from Panel Data before and after the Great East Japan Earthquake." The authors thank Fernando Aragon, Daniel Benjamin, Prashant Bharadwaj, Michael Callen, John Cawley, Pascaline Dupas, Catherine Eckel, Hiroyuki Kasahara, Jaimie Lien, Krishna Pendakur, Luigi Pistaferri, Yasuyuki Sawada, Kensuke Teshima, Eric Weese, and seminar participants at the Canadian Economic Association Meeting, Chukyo University, Colgate University, Cornell PAM, CUHK, GRIPS, HKUST, ISER, Keio University, Kyoto Summer Workshop on Applied Economics, NBER Japan meeting, Osaka University, Otaru University of Commerce, Simon Fraser University, Tohoku University, Tokyo Labor Economic Workshop, University of Tokyo, The Society for Risk Analysis Annual Conference, 20th International Panel Data Conference (at Hitotsubashi University), and 14th Panel Survey Conference (at Institute for Research on Household Economics) for their suggestions. This research utilizes the micro data from the Preference Parameters Study of Osaka University s 21st Century COE Program "Behavioral Macrodynamics Based on Surveys and Experiments" and its Global COE project "Human Behavior and Socioeconomic Dynamics" (investigators: Yoshiro Tsutsui, Fumio Ohtake, and Shinsuke Ikeda). The views expressed herein are those of the authors and do not necessarily reflect the views of the National Bureau of Economic Research.

NBER working papers are circulated for discussion and comment purposes. They have not been peer-reviewed or been subject to the review by the NBER Board of Directors that accompanies official NBER publications.

(C) 2015 by Chie Hanaoka, Hitoshi Shigeoka, and Yasutora Watanabe. All rights reserved. Short sections of text, not to exceed two paragraphs, may be quoted without explicit permission provided that full credit, including $\odot$ notice, is given to the source. 
Do Risk Preferences Change? Evidence from Panel Data before and after the Great East Japan

Earthquake

Chie Hanaoka, Hitoshi Shigeoka, and Yasutora Watanabe

NBER Working Paper No. 21400

July 2015, Revised February 2017

JEL No. C23,D81,J16,Q54

\section{$\underline{\text { ABSTRACT }}$}

We investigate whether individuals' risk preferences change after experiencing a natural disaster, specifically, the 2011 Great East Japan Earthquake. Exploiting the panels of nationally representative surveys on risk preferences, we find that men who experienced greater intensity of the Earthquake became more risk tolerant after the Earthquake. Furthermore, these men gamble more, which is consistent with the direction of changes in risk preferences. We find no such pattern for women. Finally, the effects on men's risk preferences are persistent even five years after the Earthquake at almost the same magnitude as those shortly after the Earthquake.

Chie Hanaoka

Faculty of Economics

Kyoto Sangyo University

Kamigamo-Motoyama

Kita-ku, Kyoto, JAPAN

hanaoka@cc.kyoto-su.ac.jp

Hitoshi Shigeoka

Department of Economics

Simon Fraser University

8888 University Drive, WMC 4653

Barnaby, BC V5A 1S6

CANADA

and NBER

hitoshi_shigeoka@sfu.ca
Yasutora Watanabe

Department of Economics

HKUST Business School

Hong Kong University of Science

and Technology

Clear Water Bay, Kowloon

HONG KONG

yasutora@ust.hk 


\section{Introduction}

Risk preferences are fundamental determinants of individual decision-making about economic behavior, such as saving, investment, and consumption. Standard economic models assume that individual risk preferences are stable across time (Stigler and Becker, 1977). ${ }^{1}$ More recently, a number of studies suggest that individuals' risk preferences and, hence, risk-taking behavior can be altered by a variety of negative shocks such as early-life financial experiences, financial crises, trauma from conflict or violence, and natural disasters. ${ }^{2}$ However, there is little consensus about the direction in which such negative shocks affects risk preferences. Some of these studies find that negative shocks may induce people to become more risk averse, while others find that negative shocks may make people more risk tolerant.

A common feature of these studies is that they rely on cross-sectional data collected after the negative shocks have occurred. ${ }^{3}$ This can plague the estimates in two ways. First, selective migration of particular types of individuals may bias the estimates. For example, risk-averse individuals may be more likely to leave an area after a disaster, and hence, they may not be observed in post-disaster cross-sectional data. Second, unobserved heterogeneity of individuals may produce biased estimates under cross-sectional studies. For example, individuals in areas with frequent disasters may form very different risk preferences in unobservable ways. At the same time, the local history of past disasters could be correlated with the negative shock in consideration, and hence, could bias the estimates.

In this study, we investigate whether individuals' risk preferences change after they experience a natural disaster - specifically, the 2011 Great East Japan Earthquake (the Earthquake, hereafter). In particular, we test whether individuals who live in locations that endured higher intensity of the Earthquake become either risk averse or risk tolerant.

The novelty of our study is that we use panel data of 3,221 individuals from 226 municipalities in

\footnotetext{
1 "One does not argue over tastes for the same reason that one does not argue over the Rocky Mountains — both are there, will be there next year, too, and are the same to all men" Stigler and Becker (1977).

${ }^{2}$ On one hand, Cassar et al. (2011) and Cameron and Shah (forthcoming) find increased risk aversion after exposure to natural disasters in Indonesia, and Thailand, respectively. Kim and Lee (2013) also find that those who spent their early childhood during the peak of the Korean war remain more risk averse at their adulthood. On the other hand, Eckel et al. (2009) and Voors et al. (2012) demonstrate decreased risk aversion (i.e., increased risk tolerance) after exposure to Hurricane Katrina and civil conflict in Burundi, respectively. In addition, Malmendier and Nagel (2011) show that early life financial experiences are associated with more conservative investing behavior in later life, and Cohn et al.(2015) also documents that negative shocks makes financial professionals more risk averse in laboratory experiments. Imas (2014) suggests that these inconsistent findings can be explained by individuals' differential responses to "realized" versus paper losses. See also an excellent review by Haushofer and Fehr (2014).

${ }^{3}$ Notable exceptions include Sahm (2012) and Guiso et al. (2013). Sahm (2012) uses Health and Retirement Survey to investigate the effect of life-cycle event on risk preferences but the sample is limited to the elderly over age 40 and the duration between the pairs of risk measures are 6 years on average. Guiso et al. (2013) use a repeat survey of a bank's clients to study the effect of 2008 financial crisis. Our study differs from these as our data are nationally-representative survey covering all types of individuals.
} 
a nationally representative survey. Thus, we can track the changes in risk preferences of the same individuals before and after the Earthquake to control for unobserved individual heterogeneity. Furthermore, the panel structure allows us to examine if selective migration takes place in our data.

How the Earthquake or negative shocks in general potentially alter individuals' risk preferences is not well understood. The literature points out that emotional responses to negative shocks may alter individuals' risk preferences (e.g., Lerner and Keltner, 2001; Loewenstein et al., 2001). Furthermore, psychology literature suggests that gender can be a factor influencing such emotional responses. ${ }^{4}$

We find that men who are exposed to higher intensities of the Earthquake become more risk tolerant. As for women, we occasionally find the opposite patterns (i.e., they become more risk averse) at the high-intensity locations, although the results for women are not very robust. While previous studies show that men are less risk averse than women in many dimensions, ${ }^{5}$ to the best of our knowledge, ours is the first study that documents gender differences in susceptibility of risk preferences and their direction. Our findings suggest that men's risk preferences are more likely to change than those of women and that men become less risk averse in response to a negative shock, despite their already low level of risk aversion.

In terms of magnitude, as the intensity of the Earthquake increases by 2 - which corresponds to 10-fold increase of ground acceleration - the relative risk aversion for men decreases by 5.3 percent from the mean before the Earthquake for men. Put another way, the size of the reduction is roughly half of the mean difference in relative risk aversion between men and women before the Earthquake.

Our results are robust to a number of potential concerns. First, we verify that selective migration does not occur in our setting by exploiting the panel structure of our data. Then, we conduct a variety of specification checks. Our results are hardly affected after controlling for changes in income, assets, property price, and home ownership. Moreover, our results are robust to different ways of constructing the intensity measure and risk preference measures of the Earthquake.

Throughout our study, the intensity measure used is the seismic intensity of the Earthquake (Shindo in Japanese), which is a metric of the strength of an earthquake at a specific location. We do not use other metrics, such as the level of radiation and fatality rate, because both these measures are too concentrated in a small number of municipalities and little variation exists for

\footnotetext{
${ }^{4}$ For example, Lerner et al. (2003) document that emotional responses mediate the gender differences in risk attitudes.

${ }^{5}$ See, for example, Eckel and Grossman (2008) and Croson and Gneezy (2009) for surveys of economics, and Byrnes et al. (1999) for a survey of psychology on gender differences in preferences. See also Charness and Gneezy (2012).
} 
the municipalities covered in our survey. Moreover, we add radiation level and fatality rate as controls and confirm that our results on risk preferences are robust to these controls.

In addition to the change in risk preferences, we ask whether risk-taking behavior is affected by the Earthquake. We find corroborative evidence that men who live in the hardest-hit locations gamble and drink more as the intensity of the Earthquake increases. However, because risktaking behavior is affected not only by risk preferences but also by many other factors (e.g., time preferences and peer effects), we need to view the results on risk-taking behavior with caution.

Finally, by comparing the estimates from cross-sectional and panel specifications, we demonstrate that the estimate relying on cross-sectional data collected after the negative shocks may be biased. In fact, we fail to obtain the same results using cross-sectional specification: men who were exposed to larger intensity of the Earthquake no longer become more risk tolerant. This result indicates that the estimate is biased, at least in our setting, by unobserved individual heterogeneity, which cross-sectional specification cannot fully control. In fact, we show that, at the time of the Earthquake, risk-averse individuals tended to live in locations with lower estimates of future catastrophic earthquakes, implying unobservable differences in risk preference formation before the Earthquake.

The rest of the paper is organized as follows. Section 2 describes the data, and Section 3 presents our identification strategy highlighting the difference between panel and cross-sectional specifications. Section 4 reports our findings, and Section 5 discusses their implications. Section 6 concludes.

\section{Data}

\subsection{Intensity of the Great East Japan Earthquake}

Although Japan has a long history of coping with earthquakes, the 2011 Earthquake is by far the largest in the country's history since modern measurement of earthquakes began. It is the fourth largest earthquake on record in the world with a magnitude of 9.0 on the Richter scale. The Earthquake occurred in the afternoon of March 11, 2011, triggering a tsunami and causing more than 15,800 deaths and 3,000 cases of missing people (Fire and Disaster Management Agency, 2013). One of the Earthquake's features is that its effects spread over a very wide area of East Japan in various ways. About 130,000 homes were destroyed. Both cellular and landline phones were dysfunctional over a wide area for a few days (Ministry of Internal Affairs and Communications, 2011). In addition, approximately 8.6 million households experienced power outages, and 2.3 million households, disruption in water supply (Ministry of Education, Culture, Sports, Science 
and Technology, 2012). Further planned power outages were inevitable because of the accident at the Fukushima Daiichi Nuclear Power Station.

The degree of negative shock differs significantly, depending on location. As our interest is to understand how risk preferences are affected by negative shocks, an ideal explanatory variable would be one that captures the wide variation of negative shocks for people who suffered most severely to people who are not affected at all. One straightforward variable would be distance from the epicenter of the Earthquake. This variable, however, is not necessarily ideal because it may not necessarily capture local differences in the intensity of negative shocks - the severity with which an earthquake hits a particular location depends heavily on subsurface structure. Instead, the main explanatory variable we use is seismic intensity of the Earthquake, which is a metric of the strength of an earthquake at a specific location (see, e.g., Scawthorn, 2003). ${ }^{6}$

The seismic intensity of earthquakes (Shindo) is constructed by the Japanese Meteorological Association (JMA). ${ }^{7}$ The JMA operates more than 1,700 monitoring stations to measure the intensity of earthquakes at each location. People in Japan are very familiar with this intensity measure, Shindo. In fact, Shindo is regularly used in media coverage for intensity of an earthquake at each location (it is similar to a weather report). We focus on seismic intensities measured for the main Earthquake on March 11, 2011. Approximately, an increase of the seismic intensity by two means 10-fold of acceleration (See Appendix A for details). Our intensity measure is the weighted average of seismic intensities from the three closest monitoring stations, where weight is the inverse of the distance between the city hall of the municipality and each monitoring station. Our results are robust to different ways of constructing an intensity measure.

In addition, we collect data on the level of fatalities (which were largely due to the tsunami following the Earthquake) and radiation (following an accident at the Fukushima Daiichi Nuclear Power Plant). However, we use these two measures only as complementary explanatory variables for a robustness check (in Subsection 4.3) mainly because radiation and fatalities are too concentrated in a small number of municipalities and little variation exists for the municipalities covered in our nationally representative survey data (see Appendix Table A11 for details of these variables).

Figure 1 shows the intensity of the Earthquake measured by Shindo in quintiles, together with the location of the epicenter. The darker color indicates higher levels of intensity. As the intensity of an earthquake depends not only on distance from the epicenter but subsurface structure, there are reasonable variations in intensity measure, even within the same distance from the epicenter. ${ }^{8}$ Of

\footnotetext{
${ }^{6}$ The magnitude of an earthquake is a metric of the energy released by the earthquake, and hence, takes a single value for each earthquake, while seismic intensity varies by location.

${ }^{7}$ Torch (2011) uses seismic intensity as a proxy for maternal stress to study the effects of stress on birth outcomes.

${ }^{8}$ The correlation between the distance from the epicenter of the Earthquake and our seismic intensity measure at the municipality level is $-0.896(\mathrm{~N}=226)$ in all locations, $-0.662(\mathrm{~N}=79)$ in locations with intensity of 4 and higher,
} 
Japan's 1,724 municipalities as of April 1, 2011, the survey covers 226 municipalities (as described in Subsection 2.2), which are shown with black outlines in Figure 1. The figure shows that our survey data cover throughout Japan, and thus, there is considerable variation in intensity level among our surveyed municipalities. In addition, the figure demonstrates that our sample includes very few coastal municipalities in the high intensity regions, where the vast majority of casualties were caused by the tsunami. In fact, of our 226 municipalities, only 6 (2.7 percent) report some population living in flooded areas. In addition, none of the 11 municipalities directly affected by the accident at the Fukushima Daiichi Nuclear Power Plant are covered in the survey.

\subsection{Panel survey on risk preference}

Our measure of risk preferences is elicited directly from a hypothetical lottery question in the Japan Household Panel Survey on Consumer Preferences and Satisfaction (JHPS-CPS) in 2011 and 2012. The JHPS-CPS is a nationally representative annual panel survey of the resident population in Japan. The sample is stratified according to two criteria: geographical area and city size. ${ }^{9}$ The data are collected using self-administered paper questionnaires, which are handdelivered to and picked up from the houses of participating households. ${ }^{10}$ The initial wave of the survey was conducted in 2003. The data before the Earthquake are from the 2011 survey and the data after the Earthquake are from the 2012 survey. ${ }^{11}$ Both surveys are conducted in January and February each year. Thus, the data before the Earthquake were collected 1 or 2 months before the Earthquake, and the data after the Earthquake were collected 10-11 months after the Earthquake.

The JHPS-CPS asks respondents about their willingness to pay for a hypothetical lottery with a 50 percent chance of winning JPY 100,000 (USD 1,000) or nothing otherwise. ${ }^{12}$ Appendix B shows the exact format of the survey question. A respondent is presented with 8 different prices in ascending order, from a price of JPY 10 (USD 0.1) in the first row of the survey question to a price of JPY 50,000 (USD 500) in the last row. For each row, starting from the first, a respondent is required to choose one of two options: buy a lottery ticket at the price (option A) or not buy the ticket (option B). Thus, the reservation price $(\lambda)$ should lie in the interval between the two prices. This is the price at which a respondent switches from option A to option B and the price in the and $-0.837(\mathrm{~N}=147)$ in locations with intensity lower than 4 .

${ }^{9}$ All municipalities are classified into 40 stratums: 10 geographical areas and 4 categories corresponding to population size. The number of sample subjects in each stratum is distributed in proportion to the resident population aged 20-69 years. The unit of sampling spot in each stratum is the census unit and is selected by random systematic sampling.

${ }^{10}$ All respondents are given a JPY 1,500 (USD 15) cash voucher by completing the survey.

${ }^{11}$ Unfortunately, we cannot use the data before 2011 because the queries on risk aversion differ from those used in 2011 and 2012 .

${ }^{12}$ This approach is similar to that used in Cramer et al. (2002), Hartog et al. (2002) and Guiso and Paiella (2008). 
row immediately before the switch. In this study, we define the reservation price as the midpoint of the two prices. ${ }^{13}$ This provides an implicit point estimate of the measure of an individual's risk preference. Note that the question we use is the only survey question eliciting risk preference in the JHPS-CPS that is available as panel data. ${ }^{14}$ Unfortunately, other important measures, such as time preferences and social preferences, are not available in the panel fashion, and thus, we do not examine them in this study.

Respondents who switch more than once (multiple switches) comprise 5.8 percent of the sample and are eliminated. ${ }^{15}$ For those who choose option A in all choices (1 percent of the sample), risk preference is estimated using the lower bound of the reservation price, that is, the price in the last decision row. Similarly, for those who choose option B in all choices (4 percent of the sample), we use the upper bound of the reservation price, that is, the price in the first decision row.

Our measure of risk preference has several advantages. First, one cannot easily isolate the change in risk preference from the change in risk perception because risk perception is likely to change when risk preference changes. However, we can identify changes in risk preferences owing to the fact that we present survey respondents with the same explicit stakes and probabilities both before and after the Earthquake. Second, because of low complexity of the lottery question in the JHPS-CPS, the nonresponse rate is quite low-2.4 percent of the original data - in contrast with a high nonresponse rate observed in previous studies with more complex questions. ${ }^{16}$ Third, while the samples in previous studies are highly restricted (e.g., to investors or clients), the measure in this study is obtained using a large nationally representative sample.

One concern of self-reported measures based on a non-incentivized hypothetical question is whether they actually reflect an individual's underlying risk traits. Several studies document that risk measures obtained by hypothetical survey questions are reliable predictors of actual risk-taking behavior (e.g., Barsky et al., 1997; Donkers et al., 2001; Anderson and Mellor, 2008; Dohmen et al., 2011). In order to check the validity of our risk measures, described in detail in what follows, we simply run regressions of risky behavior on our risk measures. One expects a negative correlation between risk-aversion measures and risk-taking behavior. Appendix Table A2 confirms the validity

\footnotetext{
${ }^{13}$ We treat the discrete variable for our risk aversion measure as continuous. Because our risk aversion measure is censored above at the price of JPY 50,000 and below at the price of JPY 10, the econometric methods should account for the censoring of the risk aversion measure. As a robustness check, we use the estimation method proposed by Honoré (1992), which explicitly accounts for the censoring of a dependent variable with fixed effects. The results are nearly identical to those using our basic specification, suggesting that our findings are likely unaffected by treating the discrete variable for our risk aversion measure as continuous (the results are available upon request).

${ }^{14}$ Because this is the only question we can use as panel data, we cannot disentangle risk preference and loss aversion as Callen et al. (2014) did, based on Andreoni and Sprenger (2011).

${ }^{15}$ As a robustness check for multiple switches, we use the first switch as the reported willingness to pay and re-estimate the models. The estimates are quantitatively unchanged (the results are available upon request).

${ }^{16}$ For example, Guiso and Paiella (2008) report a 27 percent nonresponse rate.
} 
of our risk measures; the results show a significant correlation between our risk measures and risky behavior (gambling, drinking, and smoking) with the expected signs. ${ }^{17}$

We take two approaches to convert the reservation price $(\lambda)$-obtained from a respondent's choice in hypothetical lottery - to a measure of risk aversion, following Cramer et al. (2002). We denote $Z$ as a prize of the lottery and $\alpha$ as the probability of winning the prize. In our case, $Z$ is JPY 100,000 (USD 1,000), and $\alpha$ is 0.5 , and thus, the expected value $\alpha Z$ is JPY50,000.

The first approach is a simple transformation of the reservation price:

$$
\begin{aligned}
\text { Transformed price } & =1-\lambda / \alpha Z \\
& =1-\lambda / 50,000
\end{aligned}
$$

Note that the greater a respondent's value of transformed price, the more risk averse the respondent is. In our setting, the values of transformed price only take values between zero and one, where the value of zero corresponds to the case of perfectly risk-neutral preference. ${ }^{18}$ The first table in Appendix Table A1 shows the values of transformed price in our settings.

The second approach is to use the Arrow-Pratt measure of absolute risk aversion (Pratt, 1964), $\rho=-U^{\prime \prime} / U^{\prime}$, where $U(W)$ is a standard concave utility function of wealth, $W$. In expected utility theory, the utility of wealth without participation in the lottery is equal to expected utility when participating at reservation price $\lambda: U(W)=(1-\alpha) U(W-\lambda)+\alpha U(W+Z-\lambda)$. By taking a second-order Taylor expansion around $U(W)$, we obtain an estimate of the Arrow-Pratt measure of absolute risk aversion as follows

$$
\text { Absolute risk aversion }=(\alpha Z-\lambda) /\left[(1 / 2)\left(\alpha Z^{2}-2 \alpha Z \lambda+\lambda^{2}\right)\right]
$$

See Cramer et al. (2002) for details on derivation. Note that the greater a respondent's value of absolute risk aversion, the more risk averse the respondent is. In our setting, the values of absolute risk aversion are bounded below and above in a similar manner to the transformed price, where the value of zero corresponds to the case of perfectly risk-neutral preference. The first table in Appendix Table A1 reports the values of absolute risk aversion. As shown in Subsection 4.3, our

\footnotetext{
${ }^{17}$ Another concern is that our risk measures capture only risk preferences in the financial domain. However, Dohmen et al. (2011) show that risk preferences in different domains or contexts are not perfectly but strongly correlated to each other.

${ }^{18}$ The lottery's expected value is JPY 50,000 and, thus, risk-averse individuals should be willing to pay less than JPY 50,000 while risk-loving individuals should opt to pay more than JPY 50,000. Because the maximum ticket price in our survey is indeed JPY 50,000, risk-loving individuals can only choose up to JPY 50,000, possibly underestimating risk tolerance. However, this may be of little concern because only a small fraction of respondents chooses JPY 50,000 (1.4 percent in 2011 and 1.3 percent in 2012).
} 
results are robust to the choice of two risk aversion measures. ${ }^{19}$

We also conduct analysis that does not depend how we construct these two cardinal riskpreference measures in Subsection 4.3. Specifically, we exploit the panel nature of the data, and create an ordinal risk measure that takes 1 if the choice of risk category after the Earthquake is higher (i.e., more risk-averse) than the one before the Earthquake, -1 if opposite, and 0 if there is no change. Our results are robust to using this alternative outcome.

The original data consists of 4,934 respondents in the 2011 survey. The attrition rate is fairly low at 7 percent. We focus only on those who have no missing values for the lottery question, risk-taking behavior, age, gender, and household income in both surveys. This procedure reduces the sample to 3,829. Of those remaining, 198 respondents who switched more than once in the lottery question are eliminated. Of the remaining 3,631 samples, 147 respondents who moved municipalities between surveys are eliminated. Of the remaining 3,484 samples, 263 respondents who drop from the sample in 2012 are eliminated. This produces a final sample size of 3,221 respondents located across 226 municipalities. We demonstrate in Subsection 4.2 that migration and attrition do not seem to affect our results.

We merge the JHPS-CPS data with the earthquake intensity data at the municipality level because the municipality is the most detailed unit of location available in the JHPS-CPS.

Table 1 presents the summary statistics of our final sample. The mean of transformed price, which takes a value between 0 and 1 , is 0.8 . The intensity measure of the Earthquake takes a value between 0 and 6.06 , with a mean of 2.83. The mean age of the individuals is 52.1 years and 47 percent are male. About 70 percent are employed, more than 80 percent are married, and 55 percent of educational attainment is at the level of high school graduation or below.

\section{Identification strategy}

We examine the effect of the Earthquake on risk preference using panel data before and after the Earthquake. Our identification strategy exploits the variation in the intensity of the Earthquake, while controlling for time-invariant individual characteristics using the individual fixed effects model. Our basic idea is similar to difference-in-difference: we capture the effect of the Earthquake by comparing individuals with zero intensity (control group) and non-zero intensity (treatment group), assuming that the response would have been the same in the absence of the Earthquake.

\footnotetext{
${ }^{19}$ Because both risk aversion measures are bounded above and below, we alternatively use the logit transformation of each risk preference measure as outcomes. This method is conventionally used for regression analysis when a dependent variable is a fractional variable bounded between zero and one, such as fractions (McDowell and Cox, 2001). The results using logit-transformed values are quantitatively the same (the results are available upon request). Here, we replace the 0 values in risk preference by 0.0001 when they are logit transformed.
} 
By using panel data, we can isolate the effects of the exogenous treatment (the Earthquake) by comparing the differences before and after the Earthquake across individuals who experienced different levels of intensity of the treatment. The departure from difference-in-difference is that our treatment is not binary and we can exploit the variation in intensity of the exogenous treatment.

More formally, the basic model to test whether the Earthquake influences risk preference can be written as follows

$$
Y_{i j t}=\alpha_{t}+\beta X_{j t}+\gamma Z_{i j t}+\pi W_{i}+\varepsilon_{i j t}
$$

where $\alpha_{t}$ is a year effect and $Y_{i j t}$ is a measure of risk preference for individual $i$ at location $j$ at time $t . X_{j t}$ is intensity of the Earthquake at location $j$ at time $t$ and takes the value of zero before the Earthquake. $Z_{i j t}$ represents time-varying individual characteristics, $W_{i}$ represents unobserved time-invariant individual characteristics, and $\varepsilon_{i j t}$ is a random shock. The coefficient $\alpha$ captures the effect of the Earthquake that is common to all individuals and $\beta$ measures the effect of the Earthquake on risk preference, depending on the intensity of the Earthquake.

A major econometric issue is the possible presence of unobserved individual fixed effects, $W_{i}$, such as differential risk preference formation in response to past earthquake damage. For example, individuals that have experienced severe earthquakes in the past might form different social norms and attitudes toward risk that results in unobservable differences in risk preferences (Postlewaite, 2011). At the same time, severity of the part earthquake damage could be correlated with the intensity of this Earthquake, $X_{j t}$ (e.g., because of geological factors), leading to omitted variable bias.

Fortunately, we have panel data and can take advantage of the fixed effects estimator to isolate the effects of the unobserved individual characteristics by considering the following specification

$$
\Delta Y_{i j t}=\Delta \alpha+\beta X_{j}+\gamma \Delta Z_{i j t}+\Delta \varepsilon_{i j t}
$$

where $\Delta$ indicates the difference of variables before and after the Earthquake. We denote $\Delta X_{j t}$ as $X_{j}$ for notational convenience (given that $X_{j t}=0$ for all observations before the Earthquake). The specification is difference-in-difference, with $X_{j}$ taking a continuous variable $\left(X_{j}\right.$ takes a value of zero if the intensity of the Earthquake is zero.)

If unobserved characteristics $W_{i}$ do not play an important role, the estimates from fixed effects specification (4) and the estimates using cross-sectional specification must be similar. However, we find a significant difference between the estimates from the two specifications (see Subsection 5.1), which implies the existence of potential bias resulting from the unobserved fixed effect.

In addition to the issue of unobserved fixed effects, another econometric issue is possible non- 
linearity in the effects of intensity of the Earthquake. In fact, JMA classifies an intensity level of four as a level at which "many people are frightened." Appendix A documents the definition of the JMA's intensity scale as well as its description of different levels of intensity. Reflecting the characterization of intensity scale by the JMA, our main specification considers the possibility that the effect of the Earthquake can be kinked as follows

$$
\Delta Y_{i j t}=\Delta \alpha+\beta X_{j}+\rho I\left[X_{j} \geq 4\right]\left(X_{j}-4\right)+\gamma \Delta Z_{i j t}+\Delta \varepsilon_{i j t}
$$

where the coefficient $\rho$ captures the additional linear effect of the Earthquake intensity for locations with intensity higher than four. In addition, we consider specifications in which we use $I\left[X_{j} \geq 4.5\right]$ and $I\left[X_{j} \geq 5\right]$ instead of $I\left[X_{j} \geq 4\right]$, and most of our results are robust to the change in the cut-off between 4, 4.5, and 5, as shown in Subsection 4.1. We also adopt a specification with $X$ squared instead of $I\left[X_{j} \geq 4\right]$ to account for the nonlinearity, and most of our results also remain unchanged. We estimate Equation (5) using ordinary least squares (OLS). ${ }^{20}$ We cluster the standard error at the municipality level to allow for arbitrary serial correlation within each municipality (Bertrand et al., 2004).

\section{Results}

\subsection{Main results}

Figure 2 shows the relationship between the intensity of the Earthquake and changes in risk preference. Here, we plot the changes in residual of transformed price regressed on individual characteristics. ${ }^{21}$ Each dot in the graph represents the mean of observations within each bin of 0.2 in intensity measure and the size of the dot reflects the number of observations in each bin. ${ }^{22}$ The solid fitted line is the lowess curve with a bandwidth of 0.5. Panels (a)-(c) show the figures for

\footnotetext{
${ }^{20}$ Alternatively, one could use estimation models that account for the discrete, ordinary nature of our risk aversion measure as the dependent variable. However, in short panels, it is known that the fixed effect estimators in discrete models appear to be biased substantially (e.g., Greene, 2004). Therefore, we rely on fixed effect estimation in linear models. One concern with our approach is that the risk aversion measure is treated as a continuous variable by using the midpoint of the interval between the two risk aversion categories. As a robustness check, we construct an ordinal risk aversion measure that does not rely on the interval of the risk aversion categories described in detail in Subsection 4.3. The results shown in Appendix Table A7 are essentially unchanged from our main results, suggesting that our linear model approach probably has no effect on our findings.

${ }^{21}$ Specifically, the individual controls we use are age, age squared, a female dummy (only for the full sample), income, marital status, and education. Alternatively, for robustness checks, we use the logarithm of income or the dummy variables for each income bracket instead of a continuous measure of income. The results are unchanged (the results are available upon request). As some marital status and education data are missing, we replace them with zeros and add a dummy to indicate that they are missing.

${ }^{22}$ Each bin includes 12.4 municipalities on average, ranging from 1 to 30 municipalities, and 173.5 individuals on average, ranging from 6 to 400 individuals.
} 
the full sample, men, and women, respectively. We divide the sample by gender as a large body of literature provides evidence that gender plays an important role in decision making under risk (e.g., Croson and Gneezy, 2009).

Panel (a) shows that there is no systematic change in risk aversion with respect to the intensity of the Earthquake for the full sample. However, Panel (a) masks striking gender differences shown in Panels (b) and (c) for men and women, respectively. Panel (b) shows that men who live in locations above the intensity level of roughly four become more risk tolerant as the intensity of the Earthquake increases (recall that a higher number indicates higher risk aversion). ${ }^{23}$ Interestingly, Panel (c) shows that the same pattern is not observed among women. Unlike men, we do not observe much change in risk preference after the Earthquake, except a slight increase in risk aversion at very high intensity locations.

Here, note that risk aversion is much higher among women than men at the level before the Earthquake. In fact, the mean of risk aversion (transformed price) before the Earthquake is 0.738 for men and 0.868 for women. This observation is consistent with the large body of literature that documents that men are less risk averse than women in the vast majority of environments and tasks (for reviews, see Eckel and Grossman, 2008, and Croson and Gneezy, 2009). However, the literature is silent on whether men's risk preference is more "malleable" to the experience of negative events than that of women, and to which direction risk preferences may change. Our findings suggest that men's risk preferences are more likely to change than those of women and, furthermore, that men become less risk averse, despite their already low level of risk aversion, at least in this setting.

Table 2 confirms our findings in the figures. Table 2 summarizes the estimates for running specification (5) in which the outcome is the transformed price. Note that a negative coefficient implies a decrease (increase) in the slope of risk aversion (tolerance) as the intensity of the Earthquake increases. Columns (1)-(4) show no observable or discernable relationship between the intensity of the Earthquake and risk aversion among the full sample, as can be seen in Panel (a) in Figure 2.

However, Column (5) shows that men become more risk tolerant at high intensity locations. While the estimate of intensity is slightly positive, the sign on the interaction term is negative, which suggests there is a decline in slope at an intensity of around four. Because the magnitude of the interaction term $(-0.039)$ is much larger than that of the intensity term (0.009), we can easily calculate the intensity where the change in risk aversion becomes negative, that is, where

\footnotetext{
${ }^{23}$ See the second table of Appendix Table A1 for the transition matrix of risk aversion category before and after the Earthquake (men only).
} 
men become risk tolerant. Note that in Table 2, we present this level of intensity as Value of $X$ when $\Delta Y=0$ below the row on the estimate of the constant. ${ }^{24}$ Such intensity level is 5.34, which is consistent with Panel (b) in Figure 2. Furthermore, we test the null hypothesis that individuals with intensity level, $X$ larger than 5.34 have $\Delta Y=0$. The null is rejected with a p-value of 0.02 .

With regard to magnitude, as the intensity of the Earthquake increases by 2 -which corresponds to 10-fold increase of acceleration-above the threshold of 4, our risk aversion measure decreases by $0.06[=2 \times(-0.039+0.009)]$. This corresponds to 8.1 percent reduction from the mean risk aversion of 0.738 before the Earthquake for men. Put another way, the size of the reduction is roughly half of the mean difference in risk aversion between men and women $(0.13=$ 0.868-0.738) before the Earthquake.

Columns (6) and (7) show that our estimates are robust to the alternative intensity thresholds of 4.5 and 5 ; the estimates on the interaction term are negative and statistically significant at the 1 percent level, and the magnitude of the estimates are much larger than those on $X$. As a result, the intensity level at which men become risk tolerant is very similar across specifications. Finally, Column (8) shows estimates from a more flexible form of specification. Specifically, we do not impose kink and instead include the quadratic of intensity measures. It is reassuring that the value of intensity measure when $\Delta Y=0$ is similar across these different specifications.

Interestingly, women show the opposite pattern to men. The result in Column (9) suggests that women become more risk averse at some point above an intensity of 4 , specifically, 4.9, which is consistent with Panel (c) in Figure 2. ${ }^{25}$ Note, however, that the result is barely significant in Columns (9), (10), and (12) and is not significant in Column (11). While we view the contrast between men and women as interesting, the results for women are much less robust than those for men. Thus, henceforth, we focus only on men.

\subsection{Selective migration}

Selective migration of particular types of individuals has potential to bias the estimate when postdisaster data are used. For example, risk-averse individuals may be more likely to leave an area after a disaster (Callen, forthcoming), and hence, they may not be observed in the cross-sectional data collected after the negative shock. One advantage of panel data is that, in fact, we can examine whether selective migration takes place.

First, we test the null hypothesis that the mean risk preference of those who migrated after

\footnotetext{
${ }^{24}$ Without any time-varying individual characteristics in the specification (5) (i.e., $\Delta Z_{i j t}=0$ ), such intensity $X^{*}$ should satisfy $\Delta Y=\alpha+\beta X^{*}+\rho\left(X^{*}-4\right)=0$. Thus, $X^{*}=(4 \rho+\alpha) /(\beta+\alpha)$. In similar vein, we can calculate $X^{*}$ when threshold intensities are 4.5 and 5 .

${ }^{25}$ We estimate the specification (5) fully interacted with a gender dummy and find that the slope is different between men and women at 1 percent level (results are available upon request).
} 
the Earthquake $(\mathrm{N}=60)$ and those who did not $(\mathrm{N}=1,514)$ are the same. The null could not be rejected with a p-value of 0.46 , which implies that the risk preferences of those who migrated after the Earthquake are not statistically different from those who did not.

Second, we regress a dummy for migration ( 1 if migrated after the Earthquake, and 0 otherwise) on the same set of variables as in Equation (5) to check if the migration decision is correlated with intensity of the Earthquake. Table 3 shows that migration is not systematically correlated with intensity of the Earthquake.

Both these exercises provide no evidence of selective migration after the Earthquake in our setting. This is probably because our data do not include municipalities that were hit most severely by the tsunami or directly affected by the accident at the Fukushima Daiichi Nuclear Power Plant. In our analysis, we drop individuals who migrated from the final sample because it is difficult to assign intensity of the Earthquake to such individuals. ${ }^{26}$

Furthermore, attrition may plague our results in a very similar way to selective migration. ${ }^{27}$ We conduct the same procedure to verify that attrition is not a concern in our data. We first test the null hypothesis that the mean risk preference of those who did not complete the survey after the Earthquake $(\mathrm{N}=147)$ and those who did $(\mathrm{N}=1,514)$ are the same. The null could not be rejected with a p-value of 0.975 , which implies that the risk preferences of those who did not complete the survey after the Earthquake are not statistically different from those who did. Second, we regress indicators for attrition on the same sets of variables in Equation (5) as we do for selective migration. Appendix Table A3 demonstrates that attrition is not systematically associated with intensity of the Earthquake.

\subsection{Robustness checks}

\subsubsection{Income and wealth}

An alternative explanation for our finding is that households and/or individuals hit hardest by the Earthquake gained an income windfall after the Earthquake. A significant increase in income might have an effect on risk aversion. We do not include income or assets as controls in the main regressions in Tables 2 because they are potentially endogenous.

Broadly speaking, there are two types of income windfall for households that are hit by the Earthquake. ${ }^{28}$ One source comprises income transfers from donations by the Japanese Red Cross,

\footnotetext{
${ }^{26}$ As a robustness check, we estimate the same specification as (5) using all samples in which we assign the intensity measures from the municipalities reported in 2011 to those individuals who moved between 2011 and 2012 . The results are essentially unchanged (the results are available upon request).

${ }^{27}$ The reasons for non-response are available as follows (no breakdown for men is available) : refused (51.3 percent), moved away (22.9 percent), temporarily absent (7.2 percent), and others (18.6 percent).

${ }^{28}$ Specifically, income is the total income before taxes of all earnings of a respondent's entire household, including
} 
and other organizations, channeled through local governments to affected households. Requirements for eligibility for these transfers include either the loss of a family member or the damage (half or complete) of housing. In fact, our sample of 226 municipalities includes only 25 municipalities that channeled these transfers. In addition, the possibility that the surveyed individuals in the municipality happened to be eligible for the transfer is extremely small for the municipalities in our data set because the number of surveyed individuals in each municipality is less than 15 on average. Furthermore, the amount of payment is rather small. ${ }^{29}$ Hence, by construction of the dataset, our results are unlikely to be driven by government transfers to households in these municipalities.

The second channel of income transfer is compensation from the Tokyo Electric Power Company (TEPCO) to households and organizations directly affected by the accident at the Fukushima Daiichi Nuclear Power Plant. The total cumulative payment was roughly JPY 2 trillion (about US $\$ 20$ billion) at the end of March 2013, which is about 6 times larger than payments via the first channel. Compensation to households is limited to those located in 11 municipalities within a 30-kilometer radius from the power plant or those specified by the government. None of these 11 municipalities is included in our data set. Thus, the only way TEPCO compensation could matter systematically to the individuals in our data set is through compensation to organizations, such as agricultural and fishing cooperatives. Compensation to organizations accounts for 21 percent of total compensation and payment to agricultural and fishing cooperatives (87 percent) dominates payment to organizations. However, the proportion of workers in these two industries is very small in the municipalities in our dataset. In fact, among 1,514 men in our sample, only 43 individuals (2.8 percent) work in the agriculture and fishery industries. Even if we limit the sample to individuals who live in locations hit by an intensity level of more than 4, only 20 individuals (1.3 percent) work in these two industries.

Table 4 summarizes our robustness checks against concerns about income transfer. ${ }^{30}$ To facilitate the comparison, Column (1) in Table 4 replicates the estimate from our baseline in Table 2. Column (2) adds interaction of a dummy variable of the intensity measure above four and a dummy variable that takes the value of 1 for men who work in the agriculture and fishery industries in order to capture the differential impact of the Earthquake by most affected industries. The estimates for both intensity and its interaction terms barely change, which is not surprising

bonus payments and transfers. In addition, assets comprise financial assets and house ownership; financial assets are the balance of financial assets (savings, stocks, bonds, insurance, and so on) of a respondent's entire household and house ownership is determined by whether any household member is the owner of the residence.

${ }^{29}$ For example, a family that lost one family member receives JPY 350,000 (about USD 3,500) as compensation.

${ }^{30}$ We also conduct the robustness checks for income and assets using the alternative measure of risk preference and the different intensity threshold, and find that the results are very similar (the results are available upon request). 
given that the proportion of workers in these two industries is very low. Column (3) controls for self-reported income but the estimate is again hardly affected. We need to view this result with caution because income is reported in brackets of JPY 2 million (roughly USD 20,000 in 2012), and thus, it is possible that income does indeed change within each bracket.

To compensate for the rough measure of income, even though it is far from perfect, Columns (4)-(6) show separate estimates for those who experience an increase, decrease, and no change in reported income across brackets. Column (4) shows that our results are driven mainly by men whose income does not change within brackets. Furthermore, it is reassuring that we do not observe any discernable patterns for the subsample of men who experience an income increase across brackets in Column (5).

Our results are also robust to changes in expected future income. We control for two survey measures for the percentage change in expected income 1 year or 5 years after the survey, instead of the reported change in current income, as shown in Column (3). The results remain unchanged (the results are available upon request).

In addition, we control for assets in Columns (7) and (8). Column (7) controls for assets measured in brackets of JPY 2.5 million (roughly USD 25,000) and the estimates are hardly affected. Column (8) adds a dummy that takes the value of 1 if the person owns a house but the estimates on intensity measure and its interaction are once again unaffected. ${ }^{31}$ The result is in accordance with previous literature that finds no wealth effects on elicited risk tolerance or risk-taking behavior (e.g., Sahm, 2012; Brunnermeier and Nagel, 2008). Finally, we control for the ratio of property values before and after the Earthquake at the municipality level. Column (9) shows that estimates are unchanged. ${ }^{32}$

\subsubsection{Radiation and fatalities}

Throughout the study, we use the intensity of the Earthquake as the measure of the severity of the Earthquake. However, one may argue that radiation due to the accident at the Fukushima Daiichi Nuclear Power Station may be another factor that affects people's risk preferences (Goodwin et al., 2012). ${ }^{33}$ Another possible intensity measure, which is often used in the literature (especially

\footnotetext{
${ }^{31}$ For Columns (7) and (8), we replace the missing value for assets and housing ownership with 0 , and add a dummy for such observations in the estimation. In addition, we drop these observations and perform a re-estimation, but the estimates are essentially identical.

${ }^{32}$ Data on property values are not available for five municipalities. We replace the missing value with zero and add a dummy for such observations in the estimation. We also drop these observations and perform a re-estimation but the estimates are essentially identical.

${ }^{33}$ Using the data collected 11-13 weeks after the Earthquake, Goodwin et al. (2012) show that anxiety about future earthquakes and nuclear threats is correlated with changes in both preventive actions (keeping an earthquake kit and modifying living quarters) and avoidance behavior (avoiding certain foods or going outside, wearing masks, and contemplating emigration).
} 
in violent conflicts), is the fatality rate.

As mentioned in Subsection 2.1, we do not use radiation level or fatality rate as our intensity measure in the main specification because both measures are too concentrated in a small number of municipalities and little variation exists for the municipalities covered in our sample. In fact, while the nuclear accident forced thousands of residents in the vicinity of the plant to evacuate, none of these municipalities is included in our data. In addition, a very large proportion of fatalities is due to the tsunami following the Earthquake, and again, very few municipalities in our data set have a coastline facing the Pacific Ocean, as seen in Figure 1. In fact, only 6 of 226 municipalities (2.7 percent) report non-zero population who lived in flooded areas.

Nonetheless, to assess whether radiation and fatalities are driving our results on changes in men's risk preferences, we add the level of radiation and the fatality rate for each municipality to our baseline specification (5) as controls. ${ }^{34}$ The results are summarized in Table 5.

Column (1) in Table 5 replicates the baseline estimate from Table 2 for ease of comparison across specifications. Columns (2) and (3) add the level of radiation and fatality rate, respectively, while Column (4) adds both measures simultaneously. The estimates on the interaction term are quantitatively similar to the baseline in Column (1). In addition, the estimates on radiation and fatalities are not statistically significant. ${ }^{35}$ Note that we do not claim that radiation and fatalities do not affect risk preferences; we simply do not have enough variation to precisely estimate their effects.

\subsubsection{Outliers and mean reversion}

A potential concern for the results is that they may be driven by outliers. One way to address this concern is to use M-estimation (Huber, 1964), which puts less weight on residuals that are more likely to be outliers. In addition, we reestimate the model by excluding some observations that look like outliers. The results are not different, as shown in Appendix Table A5.

\footnotetext{
${ }^{34}$ Alternatively, as a further robustness check, we exclude subjects who lived in locations hit hardest by the Earthquake from the estimation sample and re-estimate equation (5). As for radiation, we exclude subjects who lived in locations exposed to $2.3 \mu \mathrm{Sv} / \mathrm{h}$ or more, which is the level adopted as a standard for planned evacuation zones after the accident at the Fukushima Daiichi Nuclear Power Plant (20 of 226 municipalities, or 8.8 percent of the sample). As for fatalities, we exclude subjects who lived in locations that reported non-zero population who lived in flooded areas ( 6 of 226 municipalities, or 2.7 percent of the sample). The results are similar (the results are available upon request).

${ }^{35}$ Some studies show that fear of or risk perception about nuclear power plants increased after the Fukushima Daiichi Nuclear Plant accident in countries far from Japan, specifically in Germany (Goebel et al., 2013) and China (Huang et al., 2013). Therefore, one may argue that our intensity measure captures the effect of fear among those who live close to nuclear power plants other than the Fukushima Daiichi Nuclear Plant. In fact, there are 52 nuclear power plants in 18 locations across Japan. To address this concern, we control for the log distance from nearby nuclear power plants interacted with the Earthquake intensity measure. Appendix Table A4 shows that the estimates hardly change with this control. In addition, the estimate on the distance interacted with the intensity measure is not statistically significant at the conventional level.
} 
Another potential concern for the result is whether we may simply capture the mean reversion of people with high-risk aversion. However, mean reversion is not likely to drive our results. We are not aware of any event that occurred during the survey before the Earthquake for those who lived in high-intensity regions. In addition, from our data, we can show that such a concern may not be valid. We reestimate the same specification (5) in Table 2 by excluding the individuals whose risk categories are highest and second highest (categories 8 and 9 in Appendix Table A1) before the Earthquake. Our estimates remain unchanged, as shown in Appendix Table A6. ${ }^{36}$

\subsubsection{Alternative measures of risk preference}

To examine whether our results are driven by a particular form of risk preference measure, we consider two alternative ways to measure risk preferences. First, we construct another cardinal measure of risk preference defined by Equation (2) in Subsection 2.2, absolute risk aversion. We estimate our baseline specification (Equation (5)) using this alternative risk aversion measure in Appendix Table A7. The results show similar patterns to the corresponding columns in Table 2 , though the estimate on square of intensity measure in Column (4) is marginally insignificant. Though the coefficients across the two tables are not comparable due to the difference in the definition of the two measures, the intensity level at which men become more risk tolerant is similar across specifications. Using the estimates from Column (1) in Appendix Table A7, as the intensity of the Earthquake increases by 2 above the threshold of 4, absolute risk aversion decreases by $0.094[=2 \times(-0.059+0.012)]$, which corresponds to 5.3 percent reduction off the mean of 1.758 before the Earthquake. Note that since the relative risk aversion is approximately the product of absolute risk aversion and wealth (Cramer et al., 2002; Hartog et al., 2002), the change in the relative risk aversion is also 5.3 percent, which is the same as that of the absolute risk aversion. Alternatively, the size of decrease is again roughly a half of the mean difference in risk aversion between men and women $(0.177=1.935-1.758)$ before the Earthquake.

Second, as an alternative to the cardinal measure of risk preferences that we use so far, we consider an ordinal risk aversion measure. A potential concern we would like to address is that

\footnotetext{
${ }^{36}$ A natural way to examine the mean reversion would be to compare the data between 2010 (two years before the Earthquake) and 2011 (a year before the Earthquake). Unfortunately, as mentioned in Footnote 11, we cannot compare 2010 and 2011, because the questions on risk aversion before 2011 differ from those used in 2011 and 2012. Instead, we compare the data between 2009 and 2010 which asks the same (but different from those of 2011 and 2012) questions for measuring risk aversion though such comparison is not necessarily ideal because elicitation technique are different between two years (a matching technique in 2009 and a choice technique in 2010). Lévy-Garboua et al. (2011) point out that differences in elicitation technique affect the levels of risk aversion measures but we are not aware of any evidence indicating that differences in elicitation technique induce changes in these measures over the intensity of the Earthquake, which is our focus. We estimate our main specification (5) using the data in 2009 and 2010 and find no systematic difference in risk preferences measures in the pre-period years (the results are available upon request).
} 
our results could be driven by the cardinal nature of the risk aversion measure as well as potential dependence on the particular way we construct these cardinal measures. To mitigate this concern, we construct an ordinal measure that takes 1 if the choice of risk category after the Earthquake is higher (i.e., more risk-averse) than that before the Earthquake, -1 if the opposite is the case, and 0 if there is no change between the two surveys. Appendix Table A8 shows that the result is very similar using this measure. The intensity level at which the change in risk aversion becomes negative is almost the same across specifications as well as those reported in Table 2 and Appendix Table A7, where the outcomes are cardinal risk preference measures.

\subsubsection{Alternative measures of intensity}

Finally, Appendix Table A9 demonstrates the robustness of our results to different ways of constructing the intensity measure. Column (1) replicates our baseline estimates; we use the weighted average of the three closest monitoring stations. As noted in Subsection 2.1, the weight is the inverse of the distance from the city hall of each municipality to each monitoring station. Columns (2)-(4) construct the intensity measure using only the two closest monitoring stations, the simple average of intensity at the three closest stations, and the only closest station. The estimates are quantitatively similar to the baseline estimates, and thus, the intensity levels at which men become risk tolerant are quite similar across specifications. ${ }^{37}$

\section{Discussion}

\subsection{Panel vs. cross-sectional estimates}

The biggest advantage of our research design is that our data comprise a panel, and thus, we can track changes in risk preferences among the same individuals before and after the Earthquake. To the extent that unobserved time-invariant individual characteristics are correlated with both the intensity of the Earthquake and risk preference, there is potential for an omitted variable bias in the estimates obtained from cross-sectional data collected only after the negative shocks have occurred (i.e., using only "after" data), which is often the case in the literature.

\footnotetext{
${ }^{37}$ One may be concerned also with measurement error in the intensity measure. We use the location of residence to assign the severity of the Earthquake. However, the Earthquake took place on a weekday (Friday) afternoon, so some adult men were probably at work. Thus, their assigned value of earthquake severity is possibly measured with an error. To mitigate this concern, we exclude men whose commute to work takes 15 minutes or longer (remaining $\mathrm{N}=564$ ), and 30 minutes or longer (remaining $\mathrm{N}=753$ ). The results are quantitatively similar. In fact, with an intensity threshold of 4 , the value of the intensity measure (X) when $\Delta Y=0$ is 5.06 when $\mathrm{N}=564$ and 4.93 when $\mathrm{N}$ $=753$ (the results are available upon request). In any case, measurement error in the intensity measure causes our estimates to be at the lower bound because of attenuation bias.
} 
Past experience of earthquakes can be such an example, as it may be correlated with both formation of risk preferences and intensity of the Earthquake. For instance, individuals in areas that were damaged severely by earthquakes in the past might form different social norms (Postlewaite, 2011), which can affect risk preference formation in an unobserved way. At the same time, the local history of earthquakes could be correlated with the intensity of the Earthquake.

In fact, Figure 3 shows that there are substantial regional variations in pre-Earthquake risk preference measures. ${ }^{38}$ These regional variations before the Earthquake indicate that studies that rely on cross-sectional data can be biased, even if the location of the earthquake is indeed random. For example, if the earthquake occurs near regions where individuals with high (low) pre-earthquake risk measures live, a cross-sectional study may find a spurious positive (negative) relationship between the severity of the earthquake and the risk aversion measure, even in the absence of any changes in risk preferences.

While the exact reason for such regional variations is outside the scope of the current study, Figure 4 shows that before the Earthquake, risk-averse individuals indeed tended to live in locations with lower probability of future catastrophic earthquakes, predicted by a Japanese government agency using the criteria for the probability of experiencing a large earthquake in the next 30 years (see Appendix Table A11 for details of this variable). ${ }^{39}$ To the extent that such residential choice and/or formation of risk preference are driven by unobserved individual characteristics that the cross-sectional model cannot fully account for - such as physical and mental stress tolerance and susceptibility to local social norms (Postlewaite, 2011) - the estimates based on the cross-sectional data after the natural disaster can be biased, at least in this setting. ${ }^{40}$

To investigate whether such unobserved heterogeneity is present and indeed biases the estimates of cross-sectional specification in practice, we run the same specification as (5), but this time use the cross-sectional data collected after the Earthquake and compare it to the estimate from the panel specification. The results on comparing the two specifications are reported in Table 6. To facilitate the comparison, Column (1) replicates the results from the baseline specification in Table 2 using panel data. Column (2) reports the estimates based on cross-sectional data collected after

\footnotetext{
${ }^{38}$ We control for the usual individual covariates (age, age squared, income, marital status, and education) and plot the residuals.

${ }^{39}$ Interestingly, such a pattern is more apparent among women than men. Of course, it is difficult to separate whether this result reflects residential sorting (i.e., more risk-averse people migrate to safer locations) or differential formation of risk preferences at each location. Using data from Germany, Jaeger et al. (2010) and Bauernschuster et al. (2014) show that individuals who are more willing to take risks are more likely to migrate. On the other hand, Dohmen et al. (2012) document that risk preference among children is significantly related to the prevailing risk preferences in the region, controlling for parental risk preferences.

${ }^{40}$ As a robustness check, we add these pre-Earthquake hazard predictions as well as their interaction terms with intensity measure to our baseline specification (5) as controls. The estimates are unchanged (the results are available upon request).
} 
the Earthquake without any individual controls. Column (2) shows that the coefficient on the interaction term is no longer statistically significant and the magnitude of the coefficient is much smaller than the estimate reported in Column (1). In addition, the sign is different from that of Column (1). One may argue that the difference between Columns (1) and (2) is explained by a lack of proper individual controls. To address such a concern, we add observable individual controls, specifically, age, age squared, and income in Column (3). However, the estimate on the interaction term is not statistically significant at the conventional level either. ${ }^{41}$ Furthermore, the estimate on the interaction term in Column (3) barely changes from that in Column (2). This result implies that unobserved individual characteristics that are positively correlated with risk aversion are more likely to cause upward bias of the estimate obtained from cross-sectional data in our setting.

In order to test our claim further, we test the null hypothesis that the explanatory variables are uncorrelated with unobserved individual-specific error. ${ }^{42}$ If the null hypothesis were rejected, then it would be necessary to consider a model that accounts for the correlation between unobserved individual-specific error and the explanatory variables. We use a cluster-robust version of the Hausman test based on the difference between the fixed effect estimator and the random effect estimator, proposed by Wooldridge (2002). The statistics of a Wald test show the null hypothesis is rejected: 20.5 ( $\mathrm{p}$-value $=0.0001)$. Again, this finding supports the notion that the estimates obtained from a cross-sectional approach are likely to be biased.

\subsection{Risk-taking behavior}

So far, our focus has been on how the Earthquake alters individuals' risk preferences. In this section, we examine whether risk-taking behavior, such as drinking, also changes with the intensity of the Earthquake. It is important to mention that because risk-taking behavior can be affected by many factors other than risk preferences (e.g., time preferences and peer effects), we have to view the results on risk-taking behavior with caution. ${ }^{43}$

Figure 5 plots the proportion of people who drink 5 or more $12 \mathrm{oz}$-cans of beer or its equivalent almost every day. Following Figure 2, we plot the changes in outcomes of residuals regressed on individual covariates in relation to the intensity of the Earthquake. Panels (a)-(c) show the figures

\footnotetext{
${ }^{41}$ Recognizing the sample size reduction due to missing values, we further add the following controls: marital status, employment status, financial assets, house ownership, and years of education. However, the estimate is quantitatively unchanged (the results are available upon request).

${ }^{42}$ The test is conducted using the "xtoverid" command in Stata software, which is developed by Schaffer and Stillman (2006).

${ }^{43}$ Unfortunately, the survey we use does not have questions on time preference and social preference in a panel manner.
} 
for the full sample, men, and women, respectively. Panel (b) shows an increasing trend of intense drinking at very high intensity locations as the intensity of the Earthquake increases among men. While we see similar patterns among women in Panel (c), the magnitude is much smaller.

Table 7 summarizes the estimates from running specification (5) for the following three forms of risk-taking behavior for men: gambling, drinking, and smoking. ${ }^{44}$ Note that all the variables we construct here capture the most extreme form of behavior that we can observe in the data. ${ }^{45}$ Specifically, a gambling dummy takes one if the person is engaged in gambling (such as horse racing and Japanese pinball, or pachinko) at least once a week. Similarly, a smoking dummy takes 1 if the person smokes more than 30 cigarettes a day. A drinking dummy is the same variable as in Figure 5. The mean of gambling, drinking, and smoking dummies among men before the Earthquake is quite low-14.5, 2.4, and 2.4 percent, respectively.

Column (1) shows the estimates for gambling. The interaction term is positive and statistically significant, and much larger in magnitude than the negative coefficient on intensity. This result suggests that men who live in locations hit by an intensity level higher than four become more engaged in gambling as the intensity of the Earthquake increases. This result is consistent with our results that men become more risk tolerant after the Earthquake. In addition, Column (2) shows that men in these locations become more engaged in heavy drinking, even though the estimate on the interaction term is marginally statistically significant. Column (3) shows that we do not observe a similar pattern for smoking.

An alternative interpretation of our results is that men who lost their jobs because of the Earthquake have spare time for risk-taking behavior, such as gambling and drinking. However, job loss does not seem to drive our results. First, we control for the change in employment status, recognizing its endogeneity. Second, we limit the sample to men whose employment status does not change before and after the Earthquake. The point estimates are quantitatively unaffected in either case (the results are available upon request). ${ }^{46}$ For completeness, we present the result for women in Appendix Table A10. The results do not show any effects on risk-taking behavior for women. ${ }^{47}$

\footnotetext{
${ }^{44}$ Even though our risk measure is based on the financial question, our analysis on risk-taking behavior do not examine financial risk-taking behavior (e.g., saving, investment, and portfolio choice). This is because financial risktaking behavior is confounded with the change in risk perception and risk preferences. Moreover, our data includes only a very coarse measure of such behavior.

${ }^{45}$ In fact, we do not observe any statistically significant change in the mean number of drinks, gambling, and cigarettes (the results are available upon request).

${ }^{46}$ In addition, we attempt to limit the sample to retired men (i.e., those whose income and time available are less subject to change) but the sample size is too small $(\mathrm{N}=142)$ to gain any meaningful estimate.

${ }^{47}$ Note that the mean of each outcome among women before the Earthquake is by order of magnitude smaller than that of men, making it hard to detect any changes, if any.
} 


\subsection{A potential mechanism: Emotional responses}

Thus far, we show solid evidence that men who are exposed to higher intensities of the Earthquake become more risk tolerant. However, how does the experience of high intensity of the Earthquake alter men's risk preferences? The literature points out that emotional responses to negative shocks may alter risk preferences (e.g., see Loewenstein et al., 2001, for a "risk as feelings" framework). In addition, many studies document the relationship between anxiety/stress and risk-taking behavior, such as gambling and drinking (e.g., Coman et al., 1997; Dawson et al., 2005). While it is beyond the scope of our study to understand fully the mechanism behind our findings, we attempt to shed light on a potential underlying mechanism here. ${ }^{48}$

Fortunately, the survey collects three variables that may be related to the emotional stakes of respondents. Specifically, the survey asks respondents to indicate how well each of the following applies to them: feeling stressed lately ("stressed"); feeling depressed lately ("depressed"); or have not been sleeping well lately ("sleep problems"). Each variable is answered on a scale of 1-5, where 1 means "particularly true for me" and 5 means "does not hold true at all for me." Therefore, a higher score indicates that respondents have less mental/emotional issues.

Because these variables are highly positively correlated, we construct a summary index measure by taking the unweighted average of the standardized values of three emotional variables. For each variable, the standardized value is calculated by subtracting the mean and dividing by standard deviation using two years of data, so that each component of the index has a mean of zero and standard deviation of one. The aggregation improves the statistical power to detect effects that are in the same direction among similar outcomes (Kling et al., 2007). ${ }^{49}$ One limitation of this approach is that we implicitly weight each outcome equally, which may not be appropriate.

Table 8 summarizes the estimates from running specification (5), in which the outcome is the summary index measure. Note that the higher the score, the lower the mental issues of the individual (i.e., he or she is more mentally healthy). Column (1) for men shows that the interaction term is negative and statistically significant, and much larger in magnitude than the positive coefficient on intensity measure. This result suggests that men who live in locations hit by an intensity level higher than four become less mentally healthy. ${ }^{50}$ This pattern is consistent

\footnotetext{
${ }^{48}$ There is a growing body of literature in economics on the effects of emotions (e.g., fear, sadness, and anger) on decision making under risk, especially in laboratory settings in which films or stories are often used to induce emotions. For example, see Raghunathan and Pham (1999), Fehr-Duda et al. (2011), Kugler et al. (2012), Treffers et al. (2012), Drichoutis and Nayga (2013), Campos-Vazquez and Cuilty (2014), and Conte et al. (2014).

${ }^{49}$ Another approach of aggregation is to calculate the average standardized treatment effect in which the coefficient of regression for each outcome is divided by the standard deviation of each outcome to be standardized, and a simple average of all standardized coefficients is calculated. See Kling and Liebman (2004) and Finkelstein et al. (2012) for this approach to aggregation. The approach yields very similar estimates (the results are available upon request).

${ }^{50}$ Some studies document the impact of natural disasters on short- and medium-run mental health (Frankenberg
} 
with our results that men become more risk tolerant and engage more in risk-taking behavior after the Earthquake at high intensity locations. Interestingly, Column (3) shows that the estimate on the interaction term for women is not statistically significant at the conventional level. ${ }^{51}$

An alternative explanation for these results is that men who lost jobs due to the Earthquake have greater mental issues. In fact, some studies document the link between job loss and mental health (e.g., Burgard et al., 2007; Schaller and Stevens, 2014). Therefore, we control for change in employment status, once again recognizing its endogeneity, in Column (2). The estimate is essentially unchanged.

We cannot conclude that emotional responses drive our results on changes in risk preferences because there are many alternative explanations. However, it is interesting that the emotional response patterns correspond to those of risk preferences and risk-taking behavior, and that we observe such a strong pattern only among men, while the pattern among women is much weaker.

\section{Conclusion}

Attitudes toward risk under uncertainty are the key determinants of economic decision making. Standard economic models assume that risk preferences are stable across time but recent studies suggest that risk preferences may be altered by various shocks. However, little is yet known how risk preferences can be altered.

To shed light on this research question, we test whether experience of the Great East Japan Earthquake alters risk preferences of individuals. We exploit a unique panel dataset that enables us to track changes in risk preference of the same individuals before and after the Earthquake, unlike previous studies that use cross-sectional data collected only after the negative shocks occurred. Furthermore, the panel structure of our data allows us to address the issue of selective migration.

We find that men who experienced higher intensity of the Earthquake become more risk tolerant. Furthermore, we find corroborative evidence that these men become more engaged in gambling and drinking.

This study may be especially important because natural disasters are becoming increasingly prevalent all over the world, including in developed countries. Past studies have predominantly examined cases in developing countries. Our results show that the risk preferences of people in Japan - a developed country with a history of coping with frequent natural disasters - are also affected by a very large negative shock.

et al., 2008; Paxson et al., 2012; Rhodes et al., 2010).

${ }^{51}$ Note that we fail to reject the null hypothesis that the estimate on the interaction term $I\left[X_{j} \geq 4\right]\left(X_{j}-4\right)$ are the same for male and female $\left(\chi^{2}(1)=0.48\right.$ (p-value $\left.=0.4868\right)$ ). The estimates come from Columns $(2)$ and $(4)$ in Table 8 . 
Our study has some limitations. First, we can examine the effects of the Earthquake on only a limited number of risk-taking behavioral forms, such as gambling. Second, we do not examine the persistence of such changes in risk preferences because of data limitation. Third, we cannot fully understand the mechanism of how experience of high intensity of the Earthquake alters individuals' risk preferences. The intensity measures of the Earthquake we use indeed capture the degree of shock physically felt by each individual, and thus, such shocks can plausibly affect people's risk preferences. While we show some suggestive evidence of emotional responses stories, it is impossible to identify whether our results are driven entirely by the emotional responses, by other channels, or by combinations of these channels. These questions are beyond the scope of our study but clearly remain as an avenue for future research.

\section{References}

Anderson, Lisa R., and Jennifer M. Mellor. 2008. "Predicting Health Behaviors with an Experimental Measure of Risk Preference." Journal of Health Economics, 27(5): 1260-1274.

Andreoni, James, and Charles Sprenger. 2011. "Uncertainty Equivalents: Testing the Limits of the Independence Axiom." Unpublished.

Barsky, Robert B., F. Thomas Juster, Miles S. Kimball, and Matthew D. Shapiro. 1997. "Preference Parameters and Behavioral Heterogeneity: An Experimental Approach in the Health and Retirement Survey." The Quarterly Journal of Economics, 112 (2): 537-579.

Bauernschuster, Stefan, Oliver Falck, Stephan Heblich, Jens Suedekum, and Alfred Lameli. 2014. "Why are educated and risk-loving persons more mobile across regions?" Journal of Economic Behavior and Organization, 98: 56-69.

Bertrand, Marianne, Esther Duflo, and Sendhil Mullainathan. 2004. "How Much Should We Trust Differences-in-Differences Estimates?" The Quarterly Journal of Economics, 119 (1): 249-275.

Brunnermeier, Markus K., and Stefan Nagel. 2008 "Do Wealth Fluctuations Generate TimeVarying Risk Aversion? Micro-Evidence on Individuals' Asset Allocation." American Economic Review, 98(3): 713-736.

Burgard, Sarah, Jennie Brand, and James House. 2007. "Toward a Better Estimation of the Effect of Job Loss on Health." Journal of Health and Social Behavior, 48: 369-384.

Byrnes, James P., David C. Miller, and William D. Schafer. 1999. "Gender Differences in RiskTaking: A Meta-analysis." Psychological Bulletin, 125(3): 367-383. 
Callen, Michael. forthcoming. "Catastrophes and Time Preference: Evidence from the Indian Ocean Earthquake." Journal of Economic Behavior and Organization.

Callen, Michael, Mohammad Isaqzadeh, James D. Long, and Charles Sprenger. 2014. "Violence and Risk Preference: Experimental Evidence from Afghanistan." American Economic Review, 104(1): 123-148.

Cameron, Lisa, and Manisha Shah. 2015. "Risk-Taking Behavior in the Wake of Natural Disasters." Journal of Human Resources, 50(2): 484-515.

Campos-Vazquez, Raymundo M., and Emilio Cuilty. 2014. "The Role of Emotions on Risk Aversion: A Prospect Theory Experiment." Journal of Behavioral and Experimental Economics, 50: $1-9$.

Cassar, Alessandra, Andrew Healy, and Carl von Kessler. 2011. "Trust, Risk and Time Preferences after a Natural Disaster: Experimental Evidence from Thailand." Unpublished.

Charness, Gary, and Uri Gneezy. 2012. "Strong Evidence for Gender Differences in Risk Taking." Journal of Economic Behavior $\& 3$ Organization, 83(1): 50-58.

Coman, Greg J., Graham D. Burrows, and Barry J. Evans. 1997. "Stress and Anxiety as Factors in the Onset of Problem Gambling: Implications for Treatment." Stress Medicine, 13(4): 235-244.

Cohn, Alain, Jan Engelmann, Ernst Fehr, and Michel Maréchal. 2015. "Evidence for countercyclical risk aversion: an experiment with financial professionals." American Economic Review, 105(2): $860-885$

Conte, Anna, M. Vittoria Levati, and Chiara Nardi. 2014. "Risk Preferences and the Role of Emotions." Unpublished.

Cramer, Jan S., Joop Hartog, Nicole Jonker, and Mirjam van Praag. 2002. "Low Risk Aversion Encourages the Choice for Entrepreneurship: An Empirical Test of a Truism." Journal of Economic Behavior and Organization, 48(1): 29-36.

Croux, Christophe, Geert Dhaene, and Dirk Hoorelbeke. 2003. "Robust standard errors for robust estimators." Discussions Paper Series (DPS) 03.16, Center for Economic Studies.

Croson, Rachel, and Uri Gneezy. 2009. "Gender Differences in Preferences." Journal of Economic Literature, 47(2): 448-474.

Dawson, Deborah A., Bridget F. Grant, and June W. Ruan. 2005. "The Association between Stress and Drinking: Modifying Effects of Gender and Vulnerability." Alcohol and Alcoholism, 40(5): 453-460. 
Dohmen, Thomas, Armin Falk, David Huffman, Uwe Sunde, Jürgen Schupp, and Gert G. Wagner. 2011. "Individual Risk Attitudes: Measurement, Determinants and Behavioral Consequences." Journal of the European Economic Association, 9(3): 522-550.

Dohmen, Thomas, Armin Falk, David Huffman, and Uwe Sunde. 2012. "The Intergenerational Transmission of Risk and Trust Attitudes." Review of Economic Studies, 79(2): 645-677.

Donkers, Bas, Bertrand Melenberg, and Arthur van Soest. 2001. "Estimating Risk Attitudes Using Lotteries: A Large Sample Approach." Journal of Risk and Uncertainty, 22(2): 165-195.

Drichoutis, Andreas C., and Rodolfo M. Nayga Jr. 2013. "Eliciting Risk and Time Preferences under Induced Mood States." The Journal of Socio-Economics, 45: 18-27.

Eckel, Catherine C., Mahmoud A. El Gamalb, and Rick K. Wilson. 2009. "Risk Loving After the Storm: A Bayesian-Network Study of Hurricane Katrina Evacuees." Journal of Economic Behavior and Organization, 69: 110-124.

Eckel, Catherine C., and Philip J Grossman. 2008. "Men, women and risk aversion: Experimental evidence." Chapter 113. In Handbook of Experimental Economics Results, Charles R. Plott and Vernon L. Smith (eds.), Vol. 1, New York, Elsevier Press.

Fehr-Duda, Helga, Thomas Epper, Adrian Bruhin, and Renate Schubert. 2011. "Risk and Rationality: The Effects of Mood and Decision Rules on Probability Weighting." Journal of Economic Behavior and Organization, 78(1-2): 14-24.

Finkelstein, Amy, Sarah Taubman, Bill Wright, Mira Bernstein, Jonathan Gruber, Joseph P. Newhouse, Heidi Allen, Katherine Baicker, and the Oregon Health Study Group. 2012. "The Oregon Health Insurance Experiment: Evidence from the First Year." The Quarterly Journal of Economics, 127(3): 1057-1106.

Fire and Disaster Management Agency. 2013. Heisei 23 Nen Touhoku Chihou Taiheiyou Oki Jishin Ni Tsuite (Report on the Great East Japan Earthquake), Vol 149. http://www.fdma.go.jp/bn/higaihou/pdf/jishin/149.pdf (in Japanese) [accessed April 3, 2014].

Frankenberg, Elizabeth, Jed Friedman, Thomas Gillespie, Nicholas Ingwersen, Robert Pynoos, Iip Umar Rifai, Bondan Sikoki, Alan Steinberg, Cecep Sumantri, Wayan Suriastini, and Duncan Thomas. 2008. "Mental Health in Sumatra after the Tsunami." American Journal of Public Health, 98(9): 1671-1677.

Gardner, Margo, and Laurence Steinberg. 2005. "Peer Influence on Risk Taking, Risk Preference, and Risky Decision Making in Adolescence and Adulthood: An Experimental Study." Developmental Psychology, 41(4): 625-635. 
Goebel, Jan, Christian Krekel, Tim Tiefenbach, and Nicolas R. Ziebarth. 2013. "Natural Disaster, Policy Action, and Mental Well-Being: The Case of Fukushima." Unpublished.

Goodwin, Robin, Masahito Takahashi, Shaojing Sun, and Stanley O. Gaines Jr. 2012. "Modelling Psychological Responses to the Great East Japan Earthquake and Nuclear Incident." PLoS One, 7(5): e37690.

Greene, William. 2004. "The Behaviour of the Maximum Likelihood Estimator of Limited Dependent Variable Models in the Presence of Fixed Effects." Econometrics Journal, 7(1): 98-119.

Guiso, Luigi, and Monica Paiella. 2006. "The Role of Risk Aversion in Predicting Individual Behavior." In Insurance: Theoretical Analysis and Policy Implications, Chiappori, P.A., and C. Gollier (eds.), Cambridge, MIT Press.

Guiso, Luigi, and Monica Paiella. 2008. "Risk Aversion, Wealth, and Background Risk." Journal of the European Economic Association, 6(6): 1109-50.

Guiso, Luigi, Paola Sapienza, and Luigi Zingales. 2013. "Time Varying Risk Aversion." Booth Working Paper No. 13-64.

Hartog, Joop, Ada Ferrer-i-Carbonell, and Nicole Jonker. 2002. "Linking Measured Risk Aversion to Individual Characteristics." Kyklos, 55(1): 3-26.

Haushofer, Johannes, and Ernst Fehr. 2014. "On the psychology of poverty." Science, 344(6186): $862-867$.

Heckhausen, Roger A. Dixon, and Paul B. Baltes. 1989. "Gains and Losses in Development throughout Adulthood as Perceived by Different Adult Age Groups." Developmental Psychology, 25: 109-121.

Honoré, Bo E. 1992. "Trimmed Lad and Least Squares Estimation of Truncated and Censored Regression Models with Fixed Effects." Econometrica, 60(3): 533-565.

Huang, Lei, Ying Zhou, Yuting Han, James K. Hammitt, Jun Bi, and Yang Liu. 2013. "Effect of the Fukushima Nuclear Accident on the Risk Perception of Residents near a Nuclear Power Plant in China." Proceedings of the National Academy of Sciences, 110: 19742-19747.

Huber, Peter J. 1964. "Robust estimation of a location parameter." Annals of Mathematical Statistics, 35: 73-101.

Imas, Alex. 2014. "The Realization Effect: Risk-Taking After Realized Versus Paper Losses." Unpublished. 
Jaeger, David A., Thomas Dohmen, Armin Falk, David Huffman, Uwe Sunde, and Holger Bonin. 2010. "Direct Evidence on Risk Attitudes and Migration." Review of Economics and Statistics, 92: 684-689.

Jann, Ben. 2010. "ROBREG: Stata module providing robust regression estimators." Available at https://ideas.repec.org/c/boc/bocode/s457114.html [accessed September 22, 2015].

Kim, Young-Il, and Jungmin Lee. 2013. "The Long-Run Impact of Traumatic Experience on Risk Aversion." Unpublished.

Kling, Jeffrey, and Jeffrey Liebman. 2004. "Experimental Analysis of Neighborhood Effects on Youth."' Unpublished. Available at http://www.nber.org/mtopublic/483.pdf [accessed April 3, 2014].

Kling, Jeffrey, Jeffrey Liebman, and Lawrence Katz. 2007. "Experimental Analysis of Neighborhood Effects." Econometrica, 75(1): 83-119.

Kugler, Tamar, Terry Connolly and Lisa D. Ordóñez. 2012. "Emotion, Decision, and Risk: Betting on Gambles versus Betting on People." Journal of Behavioral Decision Making, 25: 123-134.

Lerner, Jennifer S., and Dacher Keltner. 2001. "Fear, Anger, and Risk." Journal of Personality and Social Psychology, 81:146-159.

Lerner, Jennifer S., Roxana M. Gonzalez, Deborah A. Small, and Baruch Fischhoff. 2003. "Effects of Fear and Anger on Perceived Risks of Terrorism: A National Field Experiment." Psychological Science, 14(2): 144-150.

Lévy-Garboua, Louis, Hela Maafi, David Masclet, and Antoine Terracol. 2012. "Risk aversion and framing effects." Experimental Economics, 15(1): 128-144.

Loewenstein, George F., Elke U. Weber, Christopher K. Hsee, and Ned Welch. 2001. "Risk as Feelings." Psychological Bulletin, 127(2): 267-286.

Malmendier, Ulrike, and Stefan Nagel. 2011. "Depression Babies: Do Macroeconomic Experiences Affect Risk Taking?" The Quarterly Journal of Economics, 126(1): 373-416.

Mather, Mara, Nina Mazar, Marissa A. Gorlick, Nichole R. Lighthall, Jessica Burgeno, Andrej Schoeke, and Dan Ariely. 2012. "Risk Preferences and Aging: The 'Certainty Effect' in Older Adults' Decision Making." Psychology and Aging, 27: 801-816.

McDowell, Allen, and Nicholas J. Cox. 2001. "Logit Transformation" Available at: http://www.stata.com/support/faqs/statistics/logit-transformation/ [accessed April 3, 2014].

Ministry of Internal Affairs and Communications. 2011. White Paper on Information and Communication in Japan Available at 
http://www.soumu.go.jp/johotsusintokei/whitepaper/eng/WP2011/2011-index.html ] [accessed April 3, 2014].

Ministry of Education, Culture, Sports, Science and Technology. 2012. White Paper on Science and Technology. Available at http://www.mext.go.jp/english/whitepaper/1323541.htm [accessed April 3, 2014].

Paxson, Christina, Elizabeth Fussell, Jean Rhodes, and Mary Waters. 2012. "Five Years Later: Recovery from Post Traumatic Stress and Psychological Distress among Low-income Mothers Affected by Hurricane Katrina." Social Science \& Medicine, 74(2):150-157.

Postlewaite, Andrew. 2011. "Social norms and preferences." Chapter 2. In Handbook for Social Economics, J. Benhabib, A. Bisin, and M. Jackson (eds.), Vol. 1A, Amsterdam and San Diego: Elsevier, North-Holland.

Pratt, John W. 1964. "Risk Aversion in the Small and in the Large." Econometrica, 32: 122-136. Raghunathan, Rajagopal, and Michel T. Pham. 1999. "All negative moods are not equal: motivational influences on anxiety and sadness on decision making." Organizational Behavior and Human Decision Processes, 79(1): 56-77.

Rhodes, Jean, Christian Chan, Christina Paxson, Cecilia E. Rouse, Mary Waters, and Elizabeth Fussell. "The Impact of Hurricane Katrina on the Mental and Physical Health of Low-Income Parents in New Orleans." American Journal of Orthopsychiatry, 80(2): 237-247.

Sahm, Claudia. 2012. "How Much Does Risk Tolerance Change?" Quarterly Journal of Finance, $2(4)$.

Scawthorn, Charles. 2003. "Earthquakes: Seismogenesis, measurement, and distribution." Chapter 4. In Earthquake Engineering Handbook, W. Chen, and C. Scawthorn (eds.), Boca Raton, FL, CRC Press.

Schaffer, Mark E., and Steven Stillman. 2006. "XTOVERID: Stata module to calculate tests of overidentifying restrictions after xtreg, xtivreg, xtivreg2, xthtaylor." Statistical Software Components S456779, Boston College Department of Economics, revised Nov 2, 2011.

Schaller, Jessamyn, and Ann Huff Stevens. 2014. "Short-run Effects of Job Loss on Health Conditions, Health Insurance, and Health Care Utilization." NBER Working Paper No. 19884.

Stigler, George J., and Gary S. Becker. 1977. "De Gustibus Non Est Disputandum." American Economic Review, 67(2): 76-90.

Torch, Florencia. 2011. "The Effect of Maternal Stress on Birth Outcomes: Exploiting a Natural Experiment." Demography, 48:1473-1491. 
Treffers, Theresa, Philipp D. Koellinger, and Arnold Picot. 2012. "In the Mood for Risk? A Random-assignment Experiment Addressing the Effects of Moods on Risk Preferences." Unpublished.

Voors, Maarten J., Eleonora E. M. Nillesen, Philip Verwimp, Erwin H. Bulte, Robert Lensink, and Daan P. Van Soest. 2012. "Violent Conflict and Behavior: A Field Experiment in Burundi." American Economic Review, 102(2): 941-964.

Wooldridge, Jeffrey M. 2002. Econometric Analysis of Cross Section and Panel Data. Cambridge, MA, MIT Press. 


\section{Appendix A: JMA seismic intensity scale (Shindo)}

Various seismic intensity scales are used in different countries to measure the degree of shaking at a specific location. The seismic intensity scale by Japanese Meteorological Association (JMA) is used in Japan and is computed using acceleration data for each monitoring station. After adjusting the raw digital acceleration data to the adjusted acceleration ( $a$ gal), the JMA seismic intensity scale $(I)$ can be obtained by $I=2 \log _{10} a+0.94$. Thus, the measure can be considered essentially as the logarithm of the acceleration. In other words, an increase of the JMA intensity scale corresponds to an exponential increase in acceleration. Approximately, an increase of JMA seismic intensity scale by two means 10 -fold of acceleration. For details, see the JMA announcement describing seismic intensity (in Japanese, last assessed on July 30, 2014) http://www.mext.go.jp/b_menu/hakusho/nc/k19960215001/k19960215001.html

The JMA's descriptions on seismic intensity for human perception and reaction as well as indoor situations are as follows.

\begin{tabular}{|c|c|c|}
\hline $\begin{array}{l}\text { Seismic } \\
\text { intensity }\end{array}$ & Human perception and reaction & Indoor situation \\
\hline $\mathbf{0}$ & $\begin{array}{l}\text { Imperceptible to people, but recorded by } \\
\text { seismometers. }\end{array}$ & - \\
\hline 1 & $\begin{array}{l}\text { Felt slightly by some people keeping } \\
\text { quiet in buildings. }\end{array}$ & - \\
\hline 2 & $\begin{array}{l}\text { Felt by many people keeping quiet in } \\
\text { buildings. Some people may be awoken. }\end{array}$ & Hanging objects such as lamps swing slightly. \\
\hline 3 & $\begin{array}{l}\text { Felt by most people in buildings. Felt by } \\
\text { some people walking. Many people are } \\
\text { awoken. }\end{array}$ & Dishes in cupboards may rattle. \\
\hline 4 & $\begin{array}{l}\text { Most people are startled. Felt by most } \\
\text { people walking. Most people are awoken. }\end{array}$ & $\begin{array}{l}\text { Hanging objects such as lamps swing } \\
\text { significantly, and dishes in cupboards rattle. } \\
\text { Unstable ornaments may fall. }\end{array}$ \\
\hline $\begin{array}{l}5 \text { Lower } \\
(4.5-5)\end{array}$ & $\begin{array}{l}\text { Many people are frightened and feel the } \\
\text { need to hold onto something stable. }\end{array}$ & $\begin{array}{l}\text { Hanging objects such as lamps swing } \\
\text { violently. Dishes in cupboards and items on } \\
\text { bookshelves may fall. Many unstable } \\
\text { ornaments fall. Unsecured furniture may } \\
\text { move, and unstable furniture may topple over. }\end{array}$ \\
\hline $\begin{array}{l}5 \text { Upper } \\
(5-5.5)\end{array}$ & $\begin{array}{l}\text { Many people find it hard to move; } \\
\text { walking is difficult without holding onto } \\
\text { something stable. }\end{array}$ & $\begin{array}{l}\text { Dishes in cupboards and items on } \\
\text { bookshelves are more likely to fall. TVs may } \\
\text { fall from their stands, and unsecured furniture } \\
\text { may topple over. }\end{array}$ \\
\hline $\begin{array}{l}6 \text { Lower } \\
(5.5-6)\end{array}$ & It is difficult to remain standing. & $\begin{array}{l}\text { Many items of unsecured furniture move and } \\
\text { may topple over. Doors may become wedged } \\
\text { shut. }\end{array}$ \\
\hline $\begin{array}{l}6 \text { Upper } \\
(6-6.5)\end{array}$ & $\begin{array}{l}\text { It is impossible to remain standing or } \\
\text { move without crawling. People may be } \\
\text { thrown through the air. }\end{array}$ & $\begin{array}{l}\text { Most items of unsecured furniture move and } \\
\text { are more likely to topple over. }\end{array}$ \\
\hline 7 & & $\begin{array}{l}\text { Most items of unsecured furniture move and } \\
\text { topple over or may even be thrown through } \\
\text { the air. }\end{array}$ \\
\hline
\end{tabular}

Source: Japan Meteorological Agency, http://www.jma.go.jp/jma/en/Activities/inttable.html 


\section{Appendix B: Survey questions on variables used in this study}

The following are survey questions used in the study.

1. Risk Preferences: Suppose there is a "speed lottery" with a 50\% chance of winning JPY 100,000 . If you win, you get the prize right away. If you lose, you get nothing. How much would you spend to buy a ticket for this lottery? Choose Option A if you would buy it at that price or choose Option B if you would not buy at that price. (X ONE Box For EACH Row)

\begin{tabular}{|c|c|c|c|}
\hline \multirow{2}{*}{\multicolumn{2}{|c|}{ Price of the "speed lottery" ticket }} & \multicolumn{2}{|c|}{$\begin{array}{l}\text { Which ONE do you prefer? } \\
\text { (X ONE Box For EACH Row) }\end{array}$} \\
\hline & & $\begin{array}{c}\text { Option A } \\
\text { (buy the "speed lottery" } \\
\text { ticket) }\end{array}$ & $\begin{array}{c}\text { Option B } \\
\text { (DO NOT buy the "speed } \\
\text { lottery" ticket) }\end{array}$ \\
\hline JPY 10 & (USD 0.1) & 1 & $2 \square$ \\
\hline JPY 2,000 & (USD 20) & $1 \square$ & $2 \square$ \\
\hline JPY 4,000 & (USD 40) & $1 \square$ & $2 \square$ \\
\hline JPY 8,000 & (USD 80) & 1 & $\square$ \\
\hline JPY 15,000 & (USD 150) & $1 \square$ & $\square$ \\
\hline JPY 25,000 & (USD 250) & $1 \square$ & $\square$ \\
\hline JPY 35,000 & (USD 350) & $1 \square$ & 口 \\
\hline JPY 50,000 & (USD 500) & $1 \square$ & $\square$ \\
\hline
\end{tabular}

Note: An exchange rate of JPY 100 = USD 1 is used.

2. Gambling: Do you bet on lotteries, casinos, sporting events, or horse races? (X ONE Box)

$1 \quad \square \quad$ Don't gamble at all

$2 \square \quad$ Used to gamble but quit gambling now

$3 \square$ Hardly gamble

$4 \quad \square \quad$ Several times a year or so

5 口 Once a month or so

$6 \quad \square \quad$ Once a week or so

$7 \quad \square \quad$ Almost everyday

3. Drinking: Do you drink alcoholic beverages? (X ONE Box)

$1 \square$ Don't drink at all

$2 \square$ Hardly drink (a few times a month or less)

$3 \square$ Drink sometimes (a few times a week)

$4 \quad \square \quad$ A can of beer (12 oz.) or its equivalent a day, almost every day

$5 \square 3$ cans of beer (12 oz. x 3) or its equivalent a day, almost every day

$6 \square \quad 5$ or more cans of beer (12 oz. x 5) or its equivalent a day, almost every day

4. Smoking: Do you smoke? (X ONE Box)

$1 \square \quad$ Never smoked

$2 \square$ Hardly smoke

$3 \square \quad$ Occasionally smoke

$4 \quad \square \quad$ I smoke about 1 to 5 cigarettes a day

$5 \square \quad$ I smoke about 6 to 10 cigarettes a day

$6 \square \quad$ I smoke about 11 to 20 cigarettes a day

$7 \quad \square \quad$ I smoke about 21 to 30 cigarettes a day

$8 \square \quad$ I smoke about 31 to 40 cigarettes a day

$9 \square \quad$ I smoke 41 cigarettes or more a day

$10 \square \quad$ I used to smoke but I quit 
Figure 1. Seismic Intensity of the Great East Japan Earthquake

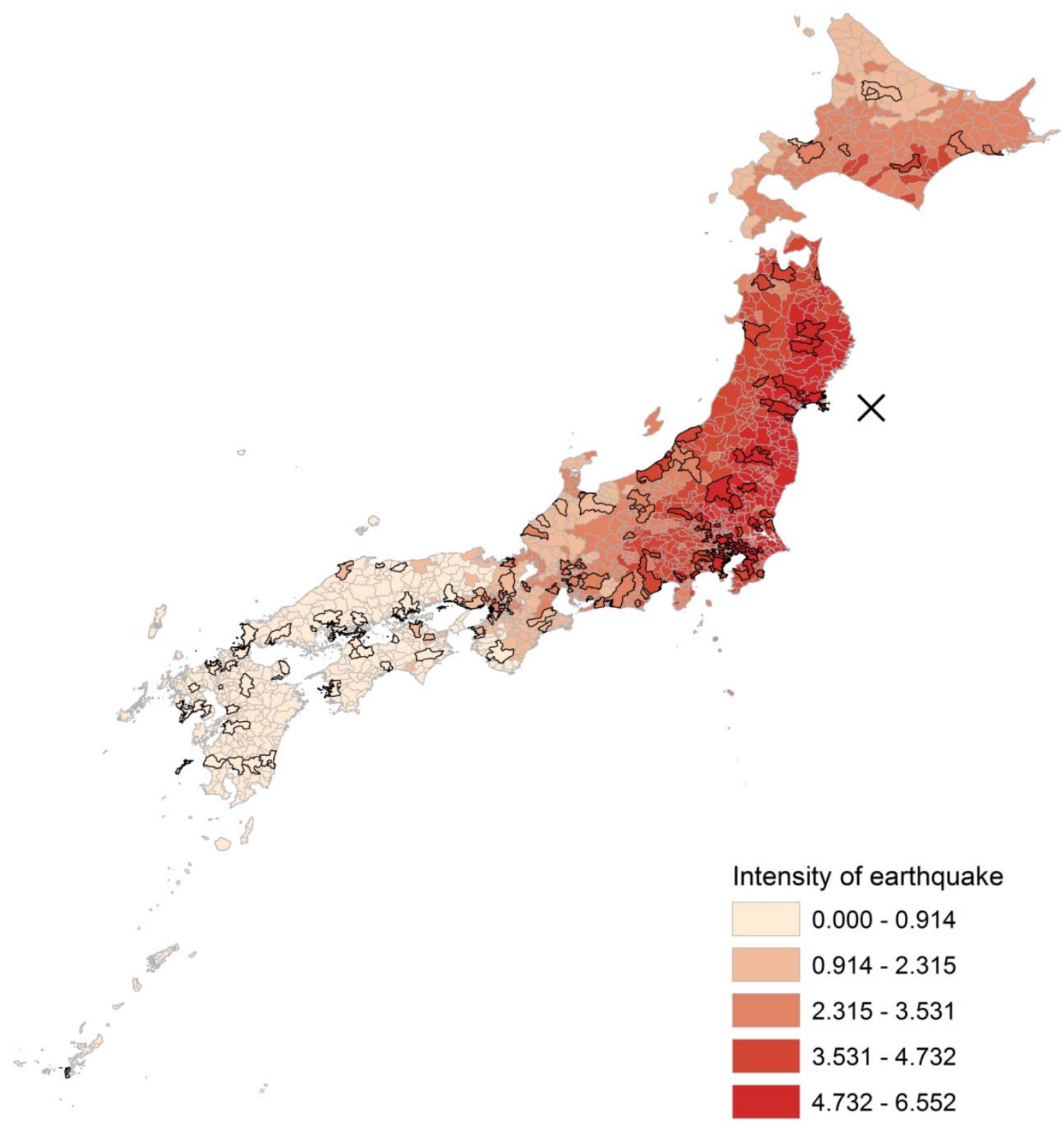

Note: The epicenter of the Earthquake $\left(38.322^{\circ} \mathrm{N} 142.369^{\circ} \mathrm{E}\right)$ is marked with a cross. Of the 1,724 municipalities in Japan on April 1, 2011, 226 municipalities in our survey are shown with black outline. The intensity of the earthquake comes from the seismic intensity of the Earthquake (Shindo in Japanese), which is a metric of the strength of the earthquake at a specific location, and is constructed by the Japanese Meteorological Association (JMA). See the main text for construction of our measure and Appendix Table A13 for the source. 
Figure 2. The changes in risk preferences and the intensity of the Earthquake

Outcome: Transformed price

(a) Full Sample

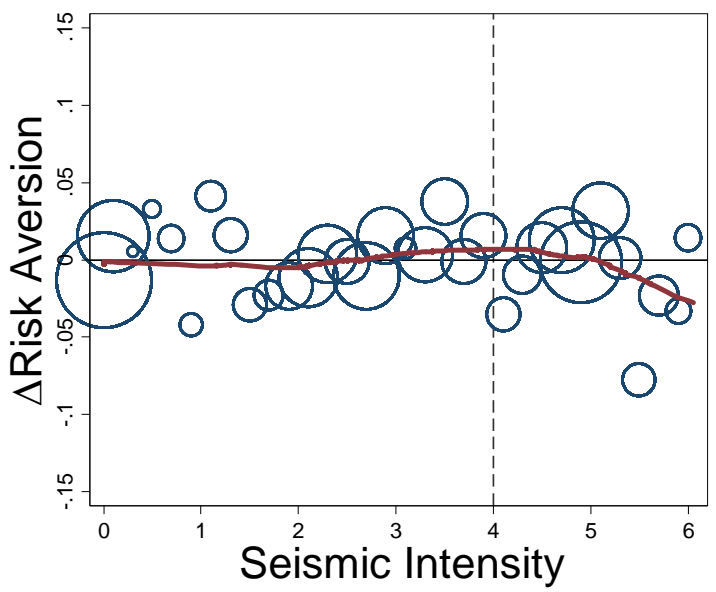

(b) Men

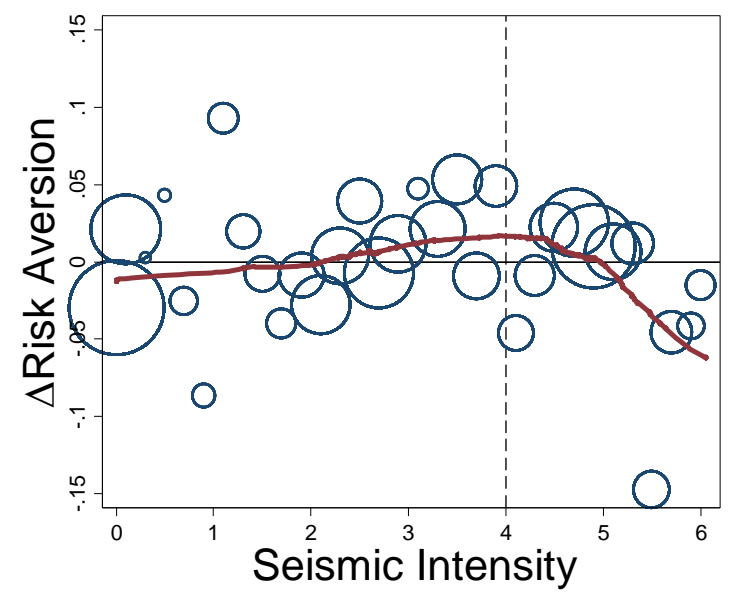

(c) Women

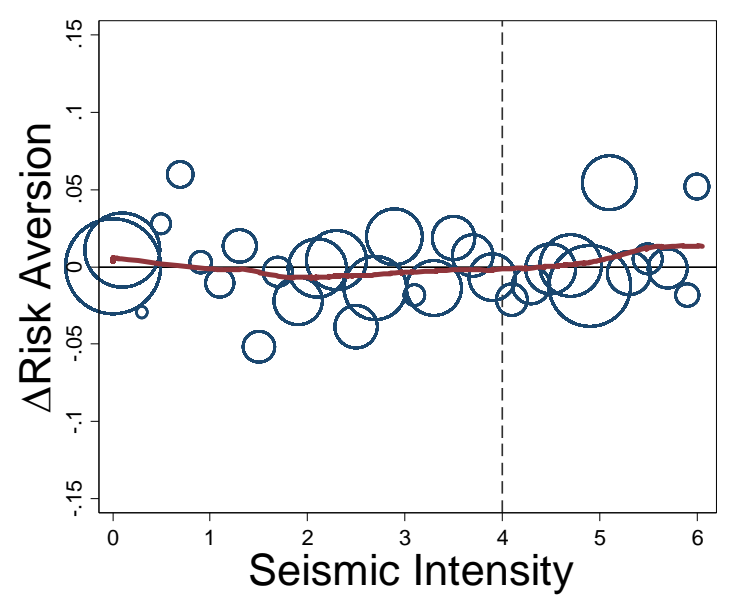

Note: The data are from the JHPS-CPS. Risk aversion on the y-axis is the transformed price. See the main text for construction of the variable. The seismic intensity of the Earthquake (Shindo in Japanese) on the x-axis is a metric of the strength of the earthquake at a specific location. We plot the changes in residual of transformed price regressed on individual characteristics (age, age-squared, gender (for full sample only), income, marital status, and years of education). Each dot in the graph represents the mean of observations within each bin of 0.2 in intensity measure and the size of the dot reflects the number of observations in each bin. The solid fitted line is a lowess curve with a bandwidth of 0.5 . The vertical dotted lines correspond to seismic intensity of four. In total, there are 3,221 individuals and 226 municipalities. We address the potential concern of outliers in Section 4.3.3. 
Figure 3. Risk Preferences by Prefecture before the Earthquake

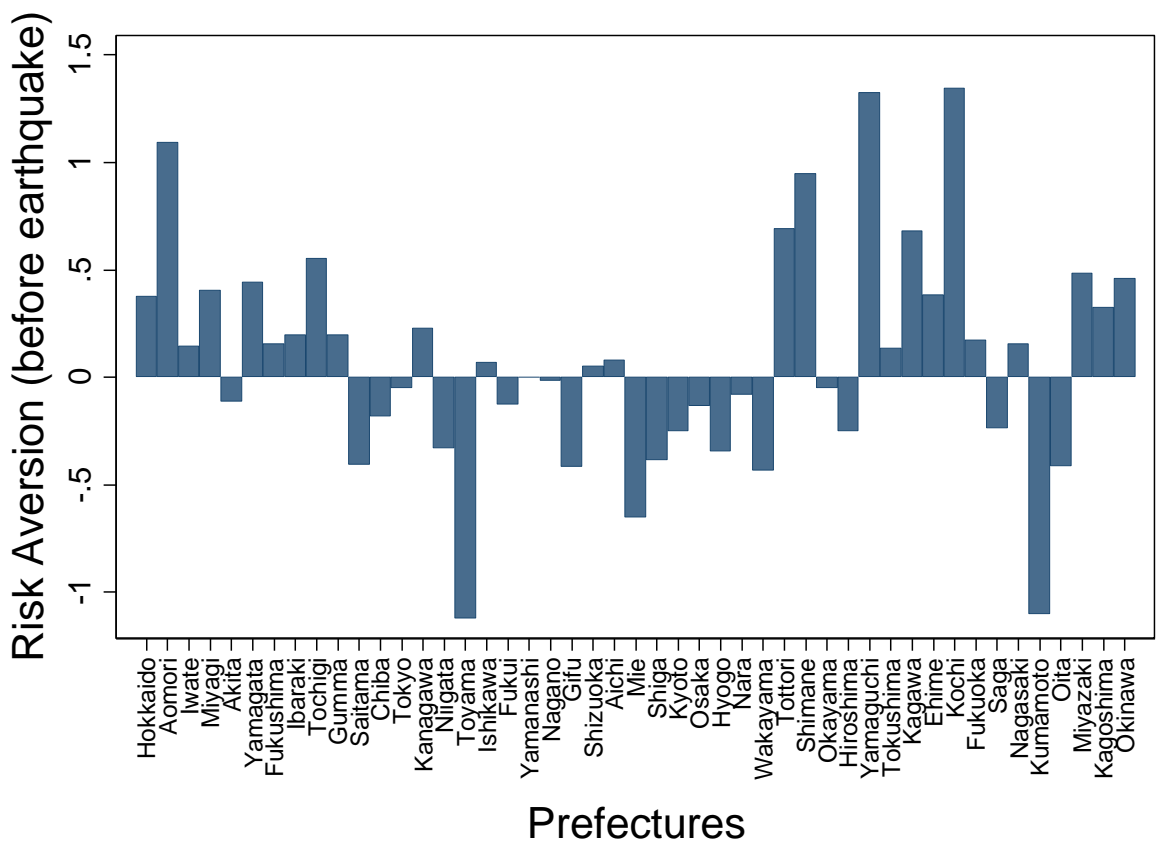

Note: Risk aversion before the Earthquake on the $y$-axis is the residual of transformed price regressed on individual characteristics (age, age-squared, gender, income, marital status, and years of education). In total, there are 47 prefectures in Japan. The null hypothesis that residualized risk aversion at each prefecture is the same is rejected at the 1 percent level $(\mathrm{F}(46,225)=265.65$, $\mathrm{p}$-value $=0.0000)$.

\section{Figure 4. Risk Preferences and Earthquake Hazard Prediction before the Earthquake}

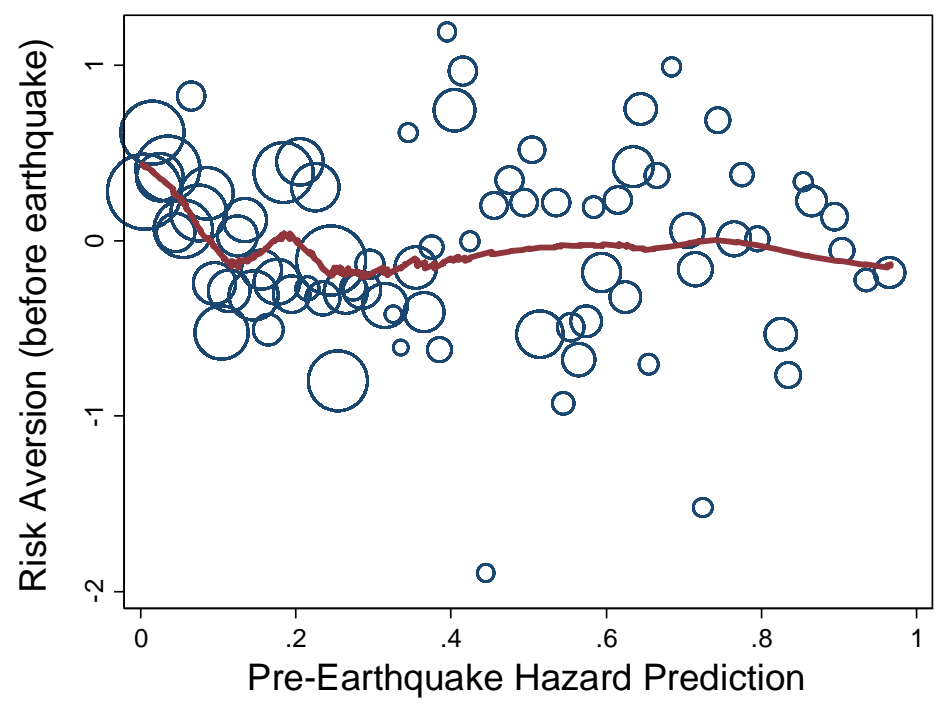

Note: Pre-Earthquake hazard prediction on the $x$-axis is the probability of future catastrophic earthquake, predicted by a Japanese government agency with the criterion being the probability of experiencing a large earthquake in the next 30 years (see Appendix Table A13 for details). Risk aversion on the $y$-axis is the residual of transformed price regressed on individual characteristics (age, age-squared, gender, income, marital status, and years of education). See the main text for construction of the variable. The line is a lowess curve with a bandwidth of 0.3. 
Figure 5. The changes in drinking behavior and the intensity of the Earthquake

Outcome: Fraction of 5 cans of beer (12 oz. per can) or its equivalent a day, almost everyday

(a) Full Sample

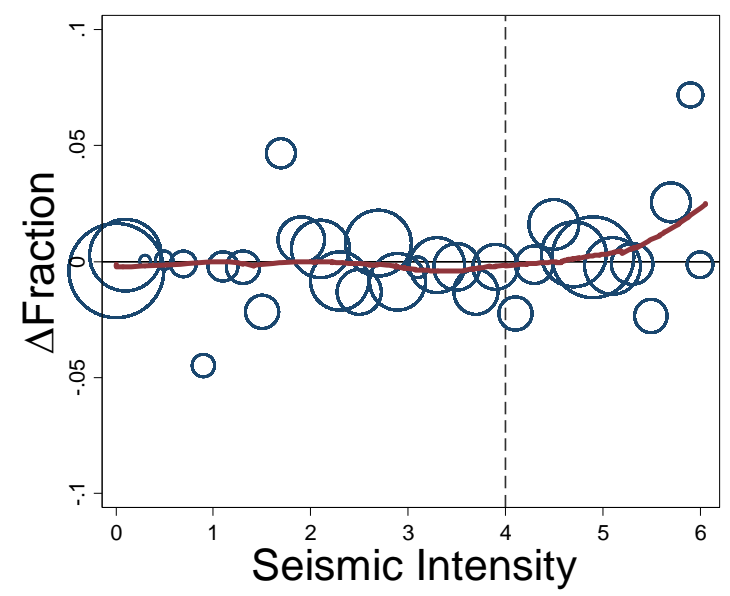

(b) Men

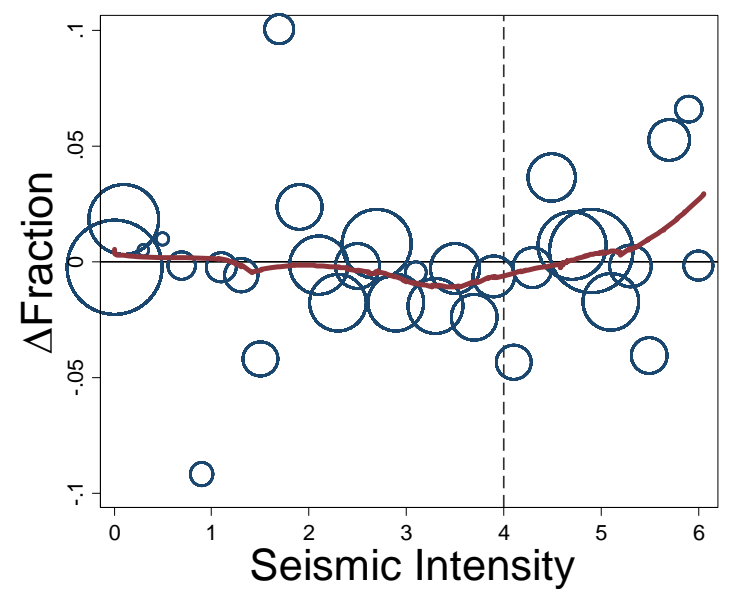

(c) Women

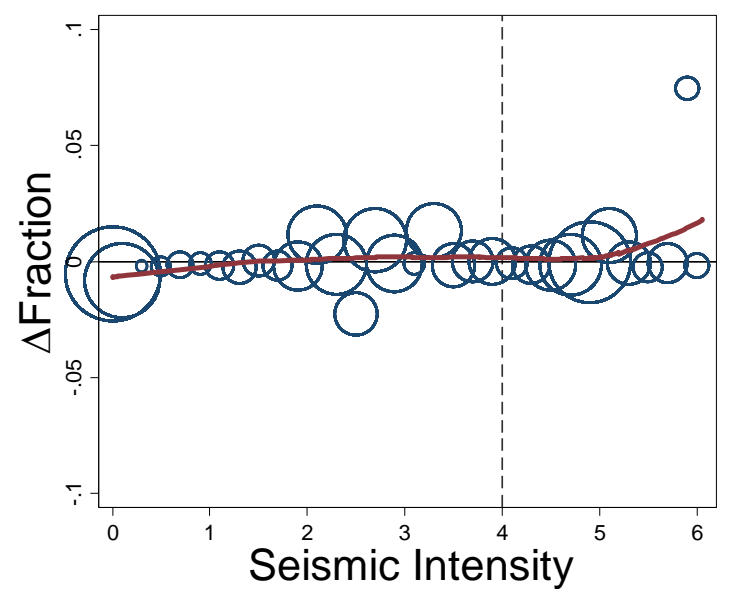

Note: The data are from the JHPS-CPS. The y-axis is the changes in residual of the fraction of people who report drinking 5 cans of beer (12 oz. per can) or its equivalent a day, almost every day, regressed on individual characteristics (age, age-squared, gender (for full sample only), income, marital status, and years of education). The seismic intensity of the Earthquake (Shindo in Japanese) on the x-axis is a metric of the strength of the earthquake at a specific location. Each dot represents the mean of observations within each bin of 0.2 and the size of the dot reflects the number of observations in each bin. The solid fitted line is a lowess curve with a bandwidth of 0.5 . The vertical dotted lines correspond to seismic intensity of four. In total, there are 3,221 individuals and 226 municipalities. 
Table 1. Summary Statistics

\begin{tabular}{lllllll}
\hline Variables & $\mathrm{N}$ & Mean & SD & Min & Max \\
\hline
\end{tabular}

A. Individual-Level Variables (before the Earthquake)

$\underline{\text { Risk Preferences }}$

\begin{tabular}{lrrrrr} 
Risk aversion measure 1 (transformed price) & 3,221 & 0.8070 & 0.2149 & 0 & 0.9998 \\
Risk aversion measure 2 (absolute risk aversion) & 3,221 & 1.8520 & 0.3568 & 0 & 2.0000 \\
Behavior & & & & & \\
\hline Gambling (once or more a week) & 3,221 & 0.09 & 0.29 & 0 & 1 \\
Drinking (5 or more cans of beer, almost every day) & 3,221 & 0.01 & 0.12 & 0 & 1 \\
Smoking (more than 30 cigarettes per day) & 3,221 & 0.01 & 0.11 & 0 & 1 \\
Individual Characteristics & & & & & \\
Age (in years) & 3,221 & 52.1 & 12.6 & 22 & 78 \\
Male & 3,221 & 0.47 & 0.50 & 0 & 1 \\
Agriculture and fishery industries & 3,221 & 0.02 & 0.15 & 0 & 1 \\
Annual household income (in JPY million) & 3,221 & 6.35 & 3.75 & 1.0 & 20 \\
Employment status & 3,221 & 0.71 & 0.45 & 0 & 1 \\
House ownership & 3,204 & 0.88 & 0.33 & 0 & 1 \\
High School graduation or less & 3,204 & 0.55 & 0.50 & 0 & 1 \\
Married & 3,171 & 0.82 & 0.38 & 0 & 1 \\
Assets (in JPY million) & 2,983 & 13.5 & 17.4 & 2.5 & 100 \\
Stress & 3,183 & 2.78 & 1.05 & 1 & 5 \\
Depression & 3,183 & 3.33 & 1.10 & 1 & 5 \\
Sleep problems & 3,183 & 3.82 & 1.08 & 1 & 5
\end{tabular}

B. Municipal-Level Variables

\begin{tabular}{lrrrrr} 
X (seismic intensity) & 226 & 2.83 & 1.94 & 0 & 6.06 \\
Property Price & 221 & 0.97 & 0.02 & 0.90 & 1.03 \\
Radiation $(\mu \mathrm{Sv} / \mathrm{h})$ & 226 & 0.10 & 0.24 & 0 & 2.40 \\
Fatality rate (per 1,000 population) & 226 & 0.25 & 2.43 & 0 & 26.9 \\
\hline
\end{tabular}

Note: See Appendix Table A13 for construction of each municipal-level variable. Note that the number of observations for assets, house ownership, education, marital status, and property price differs slightly because of missing values. Note that the values of absolute risk aversion are multiplied by 1000 . 
Table 2. Results on Risk Preferences

Outcome: Risk Aversion Measure 1 (Transformed Price)

\begin{tabular}{|c|c|c|c|c|c|c|c|c|c|c|c|c|}
\hline & \multicolumn{4}{|c|}{ Full Sample } & \multicolumn{4}{|c|}{ Men } & \multicolumn{4}{|c|}{ Women } \\
\hline & $(1)$ & (2) & (3) & (4) & (5) & (6) & (7) & (8) & (9) & $(10)$ & (11) & $(12)$ \\
\hline \multirow[t]{2}{*}{$\mathrm{X}$} & 0.003 & 0.002 & 0.002 & 0.005 & $0.009 *$ & $0.007^{*}$ & 0.005 & $0.020^{* *}$ & -0.003 & -0.002 & -0.001 & $-0.009 *$ \\
\hline & $(0.002)$ & $(0.002)$ & $(0.002)$ & $(0.005)$ & $(0.005)$ & $(0.004)$ & $(0.003)$ & $(0.010)$ & $(0.003)$ & $(0.002)$ & $(0.002)$ & $(0.005)$ \\
\hline \multirow[t]{2}{*}{$(X-4) * 1[X \geq 4]$} & -0.011 & & & & $-0.039 * *$ & & & & $0.016^{*}$ & & & \\
\hline & $(0.010)$ & & & & $(0.017)$ & & & & $(0.009)$ & & & \\
\hline \multirow[t]{2}{*}{$(X-4.5) * 1[X \geq 4.5]$} & & -0.017 & & & & $-0.058 * * *$ & & & & $0.022 *$ & & \\
\hline & & $(0.013)$ & & & & $(0.022)$ & & & & $(0.013)$ & & \\
\hline \multirow[t]{2}{*}{$(X-5) * 1[X \geq 5]$} & & & $-0.033^{*}$ & & & & $-0.093 * * *$ & & & & 0.029 & \\
\hline & & & $(0.020)$ & & & & $(0.032)$ & & & & $(0.018)$ & \\
\hline \multirow[t]{2}{*}{ X-squared } & & & & -0.001 & & & & $-0.004^{* *}$ & & & & $0.002 *$ \\
\hline & & & & $(0.001)$ & & & & $(0.002)$ & & & & $(0.001)$ \\
\hline \multirow[t]{2}{*}{ Constant } & 0.003 & 0.003 & 0.003 & 0.003 & 0.004 & 0.006 & 0.009 & 0.003 & 0.001 & 0.001 & -0.001 & 0.003 \\
\hline & $(0.005)$ & $(0.005)$ & $(0.005)$ & $(0.005)$ & $(0.011)$ & $(0.010)$ & $(0.010)$ & $(0.011)$ & $(0.006)$ & $(0.005)$ & $(0.005)$ & $(0.006)$ \\
\hline Value of $X$ when $\triangle Y=0$ & 5.65 & 5.41 & 5.40 & 6.42 & 5.34 & 5.27 & 5.37 & 5.65 & 4.90 & 5.01 & 5.23 & 4.86 \\
\hline Individual FE & $x$ & $x$ & $x$ & $x$ & $x$ & $x$ & $x$ & $x$ & $x$ & $x$ & $x$ & $x$ \\
\hline Mean of $\Delta$ risk aversion & 0.007 & 0.007 & 0.007 & 0.007 & 0.018 & 0.018 & 0.018 & 0.018 & -0.003 & -0.003 & -0.003 & -0.003 \\
\hline Mean of risk aversion (before) & 0.807 & 0.807 & 0.807 & 0.807 & 0.738 & 0.738 & 0.738 & 0.738 & 0.868 & 0.868 & 0.868 & 0.868 \\
\hline No. of individuals & 3,221 & 3,221 & 3,221 & 3,221 & 1,514 & 1,514 & 1,514 & 1,514 & 1,707 & 1,707 & 1,707 & 1,707 \\
\hline R-squared & 0.000 & 0.001 & 0.001 & 0.000 & 0.004 & 0.004 & 0.005 & 0.002 & 0.002 & 0.002 & 0.001 & 0.002 \\
\hline
\end{tabular}

Note: $\mathrm{X}$ is the seismic intensity of the Earthquake (Shindo in Japanese), a metric of the strength of an earthquake at a specific location. Significance levels are *p $<$ $0.10,{ }^{* *} \mathrm{p}<0.05$, and $* * * \mathrm{p}<0.01$. Standard errors clustered at the municipality are reported in parentheses. Value of $X$ when $\Delta Y=0$ is the level of intensity measure $(X)$ where change in risk aversion $(\Delta Y)$ switches signs. 
Table 3. Selective Migration (Men Only)

\begin{tabular}{|c|c|c|c|c|}
\hline \multirow{3}{*}{ Outcome } & \multicolumn{4}{|c|}{ Men } \\
\hline & \multicolumn{4}{|c|}{ Migration } \\
\hline & (1) & (2) & (3) & (4) \\
\hline \multirow[t]{2}{*}{$\mathrm{X}$} & -0.002 & -0.001 & 0.002 & -0.012 \\
\hline & $(0.008)$ & $(0.007)$ & $(0.008)$ & $(0.019)$ \\
\hline \multirow[t]{2}{*}{$(X-4) * 1[X \geq 4]$} & 0.023 & & & \\
\hline & $(0.031)$ & & & \\
\hline \multirow[t]{2}{*}{$(X-4.5) * 1[X \geq 4.5]$} & & 0.033 & & \\
\hline & & $(0.038)$ & & \\
\hline \multirow[t]{2}{*}{$(X-5) * 1[X \geq 5]$} & & & 0.018 & \\
\hline & & & $(0.051)$ & \\
\hline \multirow[t]{2}{*}{ X-squared } & & & & 0.003 \\
\hline & & & & $(0.003)$ \\
\hline \multirow[t]{2}{*}{ Constant } & 0.089 & 0.088 & 0.086 & 0.093 \\
\hline & $(0.093)$ & $(0.093)$ & $(0.093)$ & $(0.094)$ \\
\hline Covariates & $\times$ & $\times$ & $\times$ & $\times$ \\
\hline No. of individuals & 1,574 & 1,574 & 1,574 & 1,574 \\
\hline R-squared & 0.011 & 0.012 & 0.010 & 0.011 \\
\hline
\end{tabular}

Note: Outcome is a dummy that takes one if the person moved municipalities between surveys in 2011 and 2012. The migration rate is 3.8 percent (60 of 1,574 respondents). $X$ is the seismic intensity of the Earthquake (Shindo in Japanese), a metric of the strength of an earthquake at a specific location. Significance levels are ${ }^{*} \mathrm{p}<0.10,{ }^{* *} \mathrm{p}<0.05$, and ${ }^{* * *} \mathrm{p}<0.01$. Standard errors clustered at the municipality are reported in parentheses. Covariates in Columns (2) and (4) are age, age squared, and income. Results for specifications with $(X-4.5) * 1[X \geq 4.5],(X-5) * 1[X \geq 5]$, and $X$-squared are very similar (available upon request). 
Table 4. Robustness Checks: Income and Wealth Effects (Men Only)

Outcome: Risk Aversion Measure 1 (Transformed Price)

\begin{tabular}{|c|c|c|c|c|c|c|c|c|c|}
\hline \multirow{4}{*}{ Additional Control Variables } & \multicolumn{9}{|c|}{ Men } \\
\hline & \multirow[b]{2}{*}{ Baseline } & \multirow[b]{2}{*}{$\begin{array}{l}\text { Industry } \\
\text { dummy }\end{array}$} & \multirow[b]{2}{*}{ Income } & \multicolumn{3}{|c|}{ Changes in Income Bracket } & \multirow[b]{2}{*}{ Asset } & \multirow{2}{*}{$\begin{array}{c}\text { House } \\
\text { Ownership } \\
\text { Dummy }\end{array}$} & \multirow{2}{*}{$\begin{array}{c}\text { Property } \\
\text { Price }\end{array}$} \\
\hline & & & & $\begin{array}{l}\Delta \text { Income } \\
\quad=0\end{array}$ & $\begin{array}{c}\Delta \text { Income } \\
>0\end{array}$ & $\begin{array}{c}\Delta \text { Income } \\
\quad<0\end{array}$ & & & \\
\hline & (1) & (2) & (3) & (4) & (5) & (6) & (7) & (8) & (9) \\
\hline \multirow[t]{2}{*}{$\mathrm{X}$} & $0.009 *$ & $0.009 *$ & $0.009 *$ & $0.019 * * *$ & 0.003 & -0.008 & $0.009 *$ & $0.009 *$ & $0.009 *$ \\
\hline & $(0.005)$ & $(0.005)$ & $(0.005)$ & $(0.007)$ & $(0.009)$ & $(0.011)$ & $(0.005)$ & $(0.005)$ & $(0.005)$ \\
\hline \multirow[t]{2}{*}{$(X-4) * 1[X \geq 4]$} & $-0.039 * *$ & $-0.037 * *$ & $-0.037 * *$ & $-0.074 * * *$ & 0.005 & -0.003 & $-0.037 * *$ & $-0.037 * *$ & $-0.039 * *$ \\
\hline & $(0.017)$ & $(0.017)$ & $(0.017)$ & $(0.026)$ & $(0.032)$ & (0.037) & (0.017) & $(0.017)$ & (0.017) \\
\hline \multirow[t]{2}{*}{ Constant } & 0.004 & 0.004 & 0.004 & -0.010 & 0.040 & $0.069 * *$ & 0.005 & 0.005 & 0.004 \\
\hline & $(0.011)$ & $(0.011)$ & $(0.011)$ & $(0.015)$ & $(0.032)$ & $(0.033)$ & $(0.011)$ & $(0.011)$ & (0.017) \\
\hline Individual FE & $\times$ & $\times$ & $\times$ & $\times$ & $\times$ & $\times$ & $\times$ & $\times$ & $\times$ \\
\hline Industry dummy * $1[X \geq 4]$ & & $x$ & $x$ & $x$ & $x$ & $x$ & $\times$ & $x$ & $x$ \\
\hline Income & & & $\times$ & & $\times$ & $\times$ & $\times$ & $\times$ & $\times$ \\
\hline Asset & & & & & & & $\times$ & $\times$ & $x$ \\
\hline House ownership & & & & & & & & $x$ & $x$ \\
\hline Property price & & & & & & & & & $\times$ \\
\hline Mean of $\Delta$ risk aversion & 0.018 & 0.018 & 0.018 & 0.021 & 0.010 & 0.017 & 0.018 & 0.018 & 0.018 \\
\hline Mean of risk aversion (before) & 0.738 & 0.738 & 0.738 & 0.744 & 0.730 & 0.733 & 0.738 & 0.738 & 0.738 \\
\hline No. of individuals & 1,514 & 1,514 & 1,514 & 810 & 344 & 360 & 1,514 & 1,514 & 1,514 \\
\hline R-squared & 0.004 & 0.005 & 0.005 & 0.018 & 0.015 & 0.011 & 0.005 & 0.007 & 0.004 \\
\hline
\end{tabular}

Note: $\mathrm{X}$ is the seismic intensity of the Earthquake (Shindo in Japanese), a metric of the strength of an earthquake at a specific location. Significance levels are ${ }^{*} \mathrm{p}<0.10,{ }^{* *} \mathrm{p}<0.05$, and ${ }^{* * *} \mathrm{p}<0.01$. Standard errors clustered at the municipality are reported in parentheses. Results for specifications with (X $4.5) * 1[\mathrm{X} \geq 4.5],(\mathrm{X}-5) * 1[\mathrm{X} \geq 5]$, and $\mathrm{X}$-squared are very similar (available upon request). 
Table 5. Robustness Checks: Radiation and Fatality Rate (Men Only)

Outcome: Risk Preference Measure 1 (Transformed Price)

\begin{tabular}{lcccc}
\hline & \multicolumn{5}{c}{ Men } & $(4)$ \\
\cline { 2 - 5 } & $0.009^{*}$ & $0.009^{*}$ & $0.009^{*}$ & $0.009^{*}$ \\
& $(0.005)$ & $(0.005)$ & $(0.005)$ & $(0.005)$ \\
$(\mathrm{X}-4) * 1[\mathrm{X} \geq 4]$ & $-0.039^{* *}$ & $-0.042^{* *}$ & $-0.036^{*}$ & $-0.039^{*}$ \\
& $(0.017)$ & $(0.019)$ & $(0.019)$ & $(0.020)$ \\
Radiation & & 0.013 & & 0.013 \\
& & $(0.024)$ & & $(0.025)$ \\
Fatality rate & & & -0.003 & -0.004 \\
& & & $(0.004)$ & $(0.004)$ \\
Constant & 0.004 & 0.003 & 0.004 & 0.003 \\
& $(0.011)$ & $(0.011)$ & $(0.011)$ & $(0.011)$ \\
\hline Individual FE & $\times$ & $\times$ & $\times$ & $\times$ \\
Income & $\times$ & $\times$ & $\times$ & $\times$ \\
No. of individuals & 1,514 & 1,514 & 1,514 & 1,514 \\
R-squared & 0.004 & 0.004 & 0.004 & 0.004 \\
\hline
\end{tabular}

Note: $\mathrm{X}$ is the seismic intensity of the Earthquake (Shindo in Japanese), a metric of the strength of an earthquake at a specific location. Radiation is measured in $\mu \mathrm{Sv} / \mathrm{h}$. Fatality rate is the log of the number of deaths plus 1 per 1,000,000 persons. See Appendix Table A13 for details of these variables. Significance levels are ${ }^{*} p<0.10,{ }^{* *} \mathrm{p}<0.05$, and ${ }^{* * *} \mathrm{p}<0.01$.

Standard errors clustered at the municipality are reported in parentheses. Results for specifications with $(X-4.5) * 1[X \geq 4.5],(X-5) * 1[X \geq 5]$, and $X$-squared are very similar (available upon request) 
Table 6. Results on Risk Preferences: Panel versus Cross Section (Men Only) Outcome: Risk Aversion Measure 1 (Transformed Price)

\begin{tabular}{|c|c|c|c|}
\hline \multirow{3}{*}{ Specification } & \multicolumn{3}{|c|}{ Men } \\
\hline & \multirow{2}{*}{$\frac{\text { Panel }}{(1)}$} & \multicolumn{2}{|c|}{ Cross Section } \\
\hline & & (2) & (3) \\
\hline \multirow[t]{2}{*}{$X$} & $0.009 *$ & -0.004 & -0.003 \\
\hline & $(0.005)$ & $(0.004)$ & $(0.004)$ \\
\hline \multirow[t]{2}{*}{$(X-4) * 1[X \geq 4]$} & $-0.039 * *$ & 0.011 & 0.011 \\
\hline & $(0.017)$ & $(0.017)$ & $(0.016)$ \\
\hline \multirow[t]{2}{*}{ Constant } & 0.004 & $0.765^{* * *}$ & $0.653 * * *$ \\
\hline & $(0.011)$ & $(0.011)$ & $(0.096)$ \\
\hline Individual FE & $x$ & & \\
\hline Covariates & & & $x$ \\
\hline No. of individuals & 1,514 & 1,514 & 1,514 \\
\hline No. of observations & 3,028 & 1,514 & 1,514 \\
\hline R-squared & 0.004 & 0.001 & 0.036 \\
\hline
\end{tabular}

Note: $\mathrm{X}$ is the seismic intensity of the Earthquake (Shindo in Japanese), a metric of the strength of an earthquake at a specific location. Significance levels are ${ }^{*} \mathrm{p}<0.10,{ }^{* *} \mathrm{p}<0.05$, and ${ }^{* * *} \mathrm{p}<0.01$. Standard errors clustered at the municipality are reported in parentheses. Covariates in Column (3) are age, age squared, and income. Results for specifications with $(\mathrm{X}-4.5) * 1[\mathrm{X} \geq 4.5],(\mathrm{X}-5) * 1[\mathrm{X} \geq 5]$, and $\mathrm{X}$-squared are very similar (available upon request). 
Table 7. Results on Behavior (Men Only)

\begin{tabular}{lccc}
\hline \multirow{2}{*}{ Outcomes } & \multicolumn{3}{c}{ Men } \\
\cline { 2 - 4 } & Gambling & Drinking & Smoking \\
& $(1)$ & $(2)$ & $(3)$ \\
\hline $\mathrm{X}$ & $-0.013^{* *}$ & -0.003 & -0.001 \\
& $(0.007)$ & $(0.002)$ & $(0.003)$ \\
$(\mathrm{X}-4)^{*} 1[\mathrm{X} \geq 4]$ & $0.047^{* *}$ & $0.018^{*}$ & 0.000 \\
Constant & $(0.019)$ & $(0.011)$ & $(0.010)$ \\
& $0.042^{* *}$ & 0.007 & 0.012 \\
Individual FE & $(0.018)$ & $(0.005)$ & $(0.009)$ \\
Income & $\times$ & $\times$ & $\times$ \\
Mean of $\Delta$ outcome & $\times$ & $\times$ & $\times$ \\
Mean of outcome (before) & 0.018 & 0.003 & 0.011 \\
No. of individuals & 0.145 & 0.024 & 0.024 \\
R-squared & 1,514 & 1,514 & 1,514 \\
\hline
\end{tabular}

Note: $\mathrm{X}$ is the seismic intensity of the Earthquake (Shindo in Japanese), a metric of the strength of an earthquake at a specific location. Significance levels are ${ }^{*} \mathrm{p}<0.10, * * \mathrm{p}<0.05$, and ${ }^{* * *} \mathrm{p}<0.01$. Standard errors clustered at the municipality are reported in parentheses. A gambling dummy takes one if the person is engaged in gambling once or more a week. A drinking dummy takes 1 if the person drinks 5 or more cans of beer (12 oz. per can) or its equivalent a day almost every day. A smoking dummy takes 1 if the person smokes more than 30 cigarettes per day. Results for specifications with $(X-4.5) * 1[X \geq 4.5],(X-5) *$ $1[X \geq 5]$, and $X$-squared are very similar (available upon request). 
Table 8. Emotional Responses

\begin{tabular}{lccccc}
\hline & \multicolumn{2}{c}{ Men } & & \multicolumn{2}{c}{ Women } \\
\cline { 2 - 3 } \cline { 5 - 6 } $\mathrm{X}$ & 0.011 & 0.010 & & 0.015 & 0.015 \\
& $(0.015)$ & $(0.015)$ & & $(0.015)$ & $(0.015)$ \\
$(\mathrm{X}-4) * 1[\mathrm{X} \geq 4]$ & $-0.124^{* *}$ & $-0.123^{* *}$ & & -0.071 & -0.071 \\
& $(0.051)$ & $(0.051)$ & & $(0.052)$ & $(0.053)$ \\
Employment Status & & -0.047 & & & -0.002 \\
& & & & & $(0.102)$ \\
Constant & -0.005 & -0.005 & & -0.022 & -0.022 \\
& $(0.040)$ & $(0.040)$ & & $(0.032)$ & $(0.032)$ \\
\hline Individual FE & $\times$ & $\times$ & & $\times$ & $\times$ \\
Income & $\times$ & $\times$ & & $\times$ & $\times$ \\
Employment status & & $\times$ & & & $\times$ \\
No. of individuals & 1,493 & 1,493 & & 1,690 & 1,690 \\
R-squared & 0.005 & 0.005 & & 0.001 & 0.001 \\
\hline
\end{tabular}

Note: Outcome is the simple average of the standardized values of three emotion variables: "stress," "depression," and "sleep problems." All emotion variables are based on respondents indicating on a 5-point scale how well each of the questions applies to them. The "Stress" question asked whether a respondent has been feeling stressed lately. The "Depression" question asked whether a respondent has been feeling depressed lately. The "Sleep problems" question asked whether a respondent has not been sleeping well lately. A scale of 1 means "particularly true for me" and 5 means "does not hold true at all for me." Therefore, a higher score indicates that the respondent has less mental/emotional issues (i.e., is mentally healthier). $\mathrm{X}$ is the seismic intensity of the Earthquake (Shindo in Japanese), a metric of the strength of an earthquake at a specific location. Columns (2) and (4) control for employment status. Significance levels are ${ }^{*} \mathrm{p}<0.10,{ }^{* *} \mathrm{p}<0.05$, and $* * * \mathrm{p}<0.01$. Standard errors clustered at the municipality are reported in parentheses. Results for specifications with $(X-4.5) * 1[X \geq 4.5],(X-5) * 1[X \geq 5]$, and $X$-squared are very similar (available upon request). 


\section{Online Appendix (Not for Publication)}




\section{Table A1. Risk Aversion Measures}

1. Risk aversion category, price of the lottery tickets, and risk aversion measures

\begin{tabular}{|c|c|c|c|c|c|c|c|c|c|}
\hline \multirow[b]{2}{*}{ Risk aversion category } & \multicolumn{3}{|c|}{$<-$ Less risk averse } & \multirow[b]{2}{*}{4} & \multirow[b]{2}{*}{5} & \multirow[b]{2}{*}{6} & \multicolumn{3}{|c|}{ More risk averse -> } \\
\hline & 1 & 2 & 3 & & & & 7 & 8 & 9 \\
\hline Price of the lottery tickets (JPY) & $\sim 50,000$ & $50,000 \sim 35,000$ & $35,000 \sim 25,000$ & $25,000 \sim 15,000$ & $15,000 \sim 8,000$ & $8,000 \sim 4,000$ & $4,000 \sim 2,000$ & $2,000 \sim 10$ & $10 \sim$ \\
\hline Transformed Price & $\sim 0$ & $0 \sim 0.30$ & $0.30 \sim 0.50$ & $0.50 \sim 0.70$ & $0.70 \sim 0.84$ & $0.84 \sim 0.92$ & $0.92 \sim 0.96$ & $0.96 \sim 0.99$ & $0.99 \sim$ \\
\hline Absolute Risk Aversion & $\sim 0$ & $0 \sim 1.100$ & $1.100 \sim 1.600$ & $1.600 \sim 1.879$ & $1.879 \sim 1.969$ & $1.969 \sim 1.993$ & $1.993 \sim 1.998$ & $1.998 \sim 2.000$ & $2.000 \sim$ \\
\hline
\end{tabular}

Note: The values of absolute risk aversion are multiplied by 1,000. See the main text for the construction of each risk aversion measure based on the price of the lottery tickets. 
2. Transition Matrix of Risk Aversion Category before and after the Earthquake (Men Only) a. $X \geq 4$

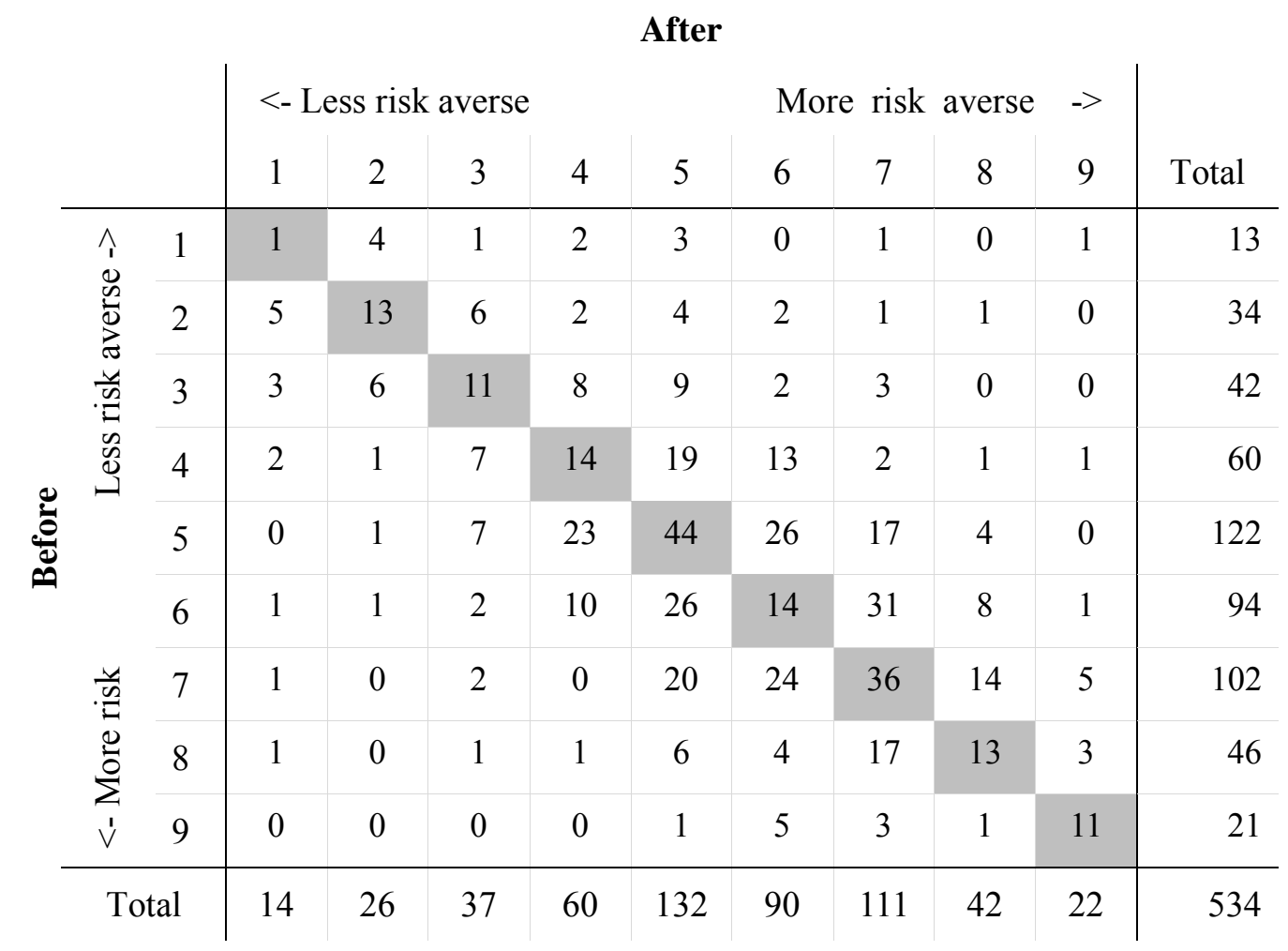

b. $X<4$

\begin{tabular}{|c|c|c|c|c|c|c|c|c|c|c|c|c|}
\hline & \multicolumn{9}{|c|}{ After } & \multirow[b]{3}{*}{ Total } \\
\hline & & & \multicolumn{5}{|c|}{$<$ - Less risk averse } & \multicolumn{3}{|c|}{ More risk averse } & $->$ & \\
\hline & & & 1 & 2 & 3 & 4 & 5 & 6 & 7 & 8 & 9 & \\
\hline \multirow{9}{*}{ } & \multirow{6}{*}{ 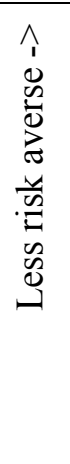 } & 1 & 4 & 5 & 4 & 6 & 5 & 1 & 2 & 0 & 0 & 27 \\
\hline & & 2 & 9 & 10 & 10 & 10 & 7 & 3 & 2 & 1 & 1 & 53 \\
\hline & & 3 & 4 & 12 & 22 & 20 & 11 & 8 & 6 & 4 & 0 & 87 \\
\hline & & 4 & 2 & 5 & 17 & 32 & 34 & 24 & 4 & 3 & 0 & 121 \\
\hline & & 5 & 0 & 3 & 10 & 34 & 91 & 47 & 37 & 7 & 3 & 232 \\
\hline & & 6 & 1 & 6 & 4 & 7 & 51 & 55 & 39 & 7 & 6 & 176 \\
\hline & \multirow{3}{*}{ 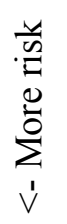 } & 7 & 1 & 1 & 3 & 6 & 29 & 43 & 60 & 30 & 7 & 180 \\
\hline & & 8 & 0 & 0 & 1 & 3 & 8 & 8 & 16 & 25 & 5 & 66 \\
\hline & & 9 & 0 & 1 & 1 & 3 & 3 & 6 & 0 & 8 & 16 & 38 \\
\hline \multicolumn{3}{|c|}{ Total } & 21 & 43 & 72 & 121 & 239 & 195 & 166 & 85 & 38 & 980 \\
\hline
\end{tabular}




\section{Table A2. The Validity of Risk Aversion Measures}

1. Using the 2011 survey (before the Earthquake)

\begin{tabular}{lccc}
\hline \multicolumn{1}{c}{ Outcomes } & Gambling & Drinking & Smoking \\
& $(1)$ & $(2)$ & $(3)$ \\
\hline Risk aversion measure 1 & $-0.146^{* * *}$ & $-0.034^{* *}$ & $-0.031^{* *}$ \\
& $(0.027)$ & $(0.014)$ & $(0.014)$ \\
Constant & $0.208^{* * *}$ & $0.041^{* * *}$ & $0.038^{* * *}$ \\
& $(0.023)$ & $(0.012)$ & $(0.012)$ \\
\hline No. of individuals & 3,221 & 3,221 & 3,221 \\
R-squared & 0.012 & 0.004 & 0.004 \\
\hline
\end{tabular}

2. Using the 2012 survey (after the Earthquake)

\begin{tabular}{lccc}
\hline \multicolumn{1}{c}{ Outcomes } & Gambling & Drinking & Smoking \\
& $(1)$ & $(2)$ & $(3)$ \\
\hline Risk aversion measure 1 & $-0.188^{* * *}$ & $-0.034^{* *}$ & -0.017 \\
& $(0.031)$ & $(0.014)$ & $(0.013)$ \\
Constant & $0.251^{* * *}$ & $0.043^{* * *}$ & $0.032^{* * *}$ \\
& $(0.026)$ & $(0.013)$ & $(0.011)$ \\
\hline No. of individuals & 3,221 & 3,221 & 3,221 \\
R-squared & 0.017 & 0.003 & 0.001
\end{tabular}

Note: Significance levels are $* p<0.10,{ }^{* *} p<0.05$, and $* * * p<0.01$. Standard errors clustered at the municipality are reported in parentheses. Risk Aversion Measure 1 is the transformed price. See the main text for construction of the variable. A gambling dummy takes one if the person is engaged in gambling once or more a week. A drinking dummy takes 1 if the person drinks 5 or more cans of beer (12 oz. per can) or its equivalent a day almost every day. A smoking dummy takes 1 if the person smokes more than 30 cigarettes per day. 
Table A3. Attrition

\begin{tabular}{|c|c|c|c|c|}
\hline \multirow{3}{*}{ Outcome } & \multicolumn{4}{|c|}{ Men } \\
\hline & \multicolumn{4}{|c|}{ Attrition } \\
\hline & (1) & (2) & (3) & (4) \\
\hline \multirow[t]{2}{*}{$\mathrm{X}$} & -0.004 & -0.002 & -0.002 & -0.019 \\
\hline & $(0.006)$ & $(0.005)$ & $(0.004)$ & $(0.013)$ \\
\hline \multirow[t]{2}{*}{$(X-4) * 1[X \geq 4]$} & 0.006 & & & \\
\hline & $(0.019)$ & & & \\
\hline \multirow[t]{2}{*}{$(X-4.5) * 1[X \geq 4.5]$} & & -0.010 & & \\
\hline & & $(0.026)$ & & \\
\hline \multirow[t]{2}{*}{$(\mathrm{X}-5) * 1[\mathrm{X} \geq 5]$} & & & -0.014 & \\
\hline & & & $(0.033)$ & \\
\hline \multirow[t]{2}{*}{$\mathrm{X}$-squared } & & & & 0.003 \\
\hline & & & & $(0.002)$ \\
\hline \multirow[t]{2}{*}{ Constant } & $0.314 * * *$ & $0.313 * * *$ & $0.314 * * *$ & $0.322 * * *$ \\
\hline & $(0.111)$ & $(0.111)$ & $(0.111)$ & $(0.110)$ \\
\hline Covariates & $\times$ & $\times$ & $\times$ & $\times$ \\
\hline No. of individuals & 1,661 & 1,661 & 1,661 & 1,661 \\
\hline R-squared & 0.006 & 0.006 & 0.006 & 0.007 \\
\hline
\end{tabular}

Note: Outcome is a dummy that takes one if the person drops from the sample in 2012 (after the Earthquake). The attrition rate is 8.9 percent (147 of 1,661 respondents). $\mathrm{X}$ is the seismic intensity of the Earthquake (Shindo in Japanese), a metric of the strength of an earthquake at a specific location. Significance levels are $* \mathrm{p}<0.10, * * \mathrm{p}<0.05$, and $* * * \mathrm{p}<0.01$. Standard errors clustered at the municipality are reported in parentheses. Covariates in Columns (2) and (4) are age, age squared, and income. Results for specifications with (X - 4.5)*1[X $\geq 4.5],(X-5) * 1[X \geq 5]$, and $\mathrm{X}$-squared are very similar (available upon request). 
Table A4. Differential Effects of Distance from Nuclear Power Plants on Risk Preferences (Men Only)

Outcome: Risk Aversion Measure 1 (Transformed Price)

\begin{tabular}{|c|c|c|c|c|c|c|c|c|}
\hline & \multicolumn{8}{|c|}{ Men } \\
\hline & (1a) & (1b) & $(2 a)$ & $(2 b)$ & (3a) & (3b) & (4a) & $(4 b)$ \\
\hline \multirow[t]{2}{*}{$\mathrm{X}$} & $0.009^{*}$ & -0.010 & $0.007^{*}$ & -0.003 & 0.005 & 0.004 & $0.020^{* *}$ & -0.004 \\
\hline & $(0.005)$ & $(0.018)$ & $(0.004)$ & $(0.019)$ & $(0.003)$ & $(0.019)$ & $(0.010)$ & $(0.021)$ \\
\hline \multirow[t]{2}{*}{$(X-4) * 1[X \geq 4]$} & $-0.039 * *$ & $-0.036^{* *}$ & & & & & & \\
\hline & $(0.017)$ & $(0.018)$ & & & & & & \\
\hline \multirow[t]{2}{*}{$(X-4.5) * 1[X \geq 4.5]$} & & & $-0.058 * * *$ & $-0.056^{* *}$ & & & & \\
\hline & & & $(0.022)$ & $(0.025)$ & & & & \\
\hline \multirow[t]{2}{*}{$(X-5) * 1[X \geq 5]$} & & & & & $-0.093 * * *$ & $-0.098 * *$ & & \\
\hline & & & & & $(0.032)$ & $(0.041)$ & & \\
\hline \multirow[t]{2}{*}{$\mathrm{X}$-squared } & & & & & & & $-0.004 * *$ & $-0.003 *$ \\
\hline & & & & & & & $(0.002)$ & $(0.002)$ \\
\hline \multirow[t]{2}{*}{$\mathrm{X} * \log$ (distance from the nearest nuclear power plant) } & & 0.004 & & 0.002 & & 0.000 & & 0.005 \\
\hline & & $(0.003)$ & & $(0.004)$ & & $(0.004)$ & & $(0.003)$ \\
\hline \multirow[t]{2}{*}{$\log$ (distance from the nearest nuclear power plant) } & & -0.011 & & -0.009 & & -0.008 & & -0.012 \\
\hline & & $(0.011)$ & & $(0.011)$ & & $(0.010)$ & & $(0.012)$ \\
\hline \multirow[t]{2}{*}{ Constant } & 0.004 & 0.054 & 0.006 & 0.048 & 0.009 & 0.043 & 0.003 & 0.057 \\
\hline & $(0.011)$ & $(0.051)$ & $(0.010)$ & $(0.050)$ & $(0.010)$ & $(0.047)$ & $(0.011)$ & $(0.053)$ \\
\hline Individual FE & $\times$ & $\times$ & $\times$ & $\times$ & $\times$ & $\times$ & $\times$ & $\times$ \\
\hline Mean of $\Delta$ risk aversion & 0.018 & 0.018 & 0.018 & 0.018 & 0.018 & 0.018 & 0.018 & 0.018 \\
\hline Mean of risk aversion (before) & 0.738 & 0.738 & 0.738 & 0.738 & 0.738 & 0.738 & 0.738 & 0.738 \\
\hline $\mathrm{N}$ of individuals & 1,514 & 1,514 & 1,514 & 1,514 & 1,514 & 1,514 & 1,514 & 1,514 \\
\hline R-squared & 0.004 & 0.004 & 0.004 & 0.005 & 0.005 & 0.005 & 0.002 & 0.003 \\
\hline
\end{tabular}

Note: $\mathrm{X}$ is the seismic intensity of the Earthquake (Shindo in Japanese), a metric of the strength of an earthquake at a specific location. Significance levels are $* \mathrm{p}<0.10,{ }^{* *} \mathrm{p}<0.05$, and ${ }^{* *} \mathrm{p}<0.01$. Standard errors clustered at the municipality are reported in parentheses. There are 52 nuclear power plants in 18 locations across Japan and we take the distance between the city hall of the municipality and the nearest nuclear power plant. 
Table A5. Robustness Checks: Outlier Analysis (Men Only)

Outcome: Risk Aversion Measure 1 (Transformed Price)

\begin{tabular}{|c|c|c|c|c|c|c|c|c|c|c|c|c|}
\hline & \multicolumn{12}{|c|}{ Men } \\
\hline & \multicolumn{4}{|c|}{ Baseline } & \multicolumn{4}{|c|}{$\begin{array}{l}\text { M-estimation } \\
\text { (Huber, 1964) }\end{array}$} & \multicolumn{4}{|c|}{$\begin{array}{l}\text { Exclude four municipalities at } X=5.5 \\
\qquad(\mathrm{~N}=26) \text { in Figure } 2\end{array}$} \\
\hline & $(1)$ & $(2)$ & $(3)$ & $(4)$ & $(5)$ & $(6)$ & $(7)$ & $(8)$ & $(9)$ & $(10)$ & $(11)$ & $(12)$ \\
\hline \multirow[t]{2}{*}{$X$} & $0.009 *$ & $0.007 *$ & 0.005 & $0.020 * *$ & $0.006^{*}$ & $0.005^{*}$ & 0.003 & $0.016^{* *}$ & $0.008^{*}$ & $0.007 *$ & $0.005^{*}$ & 0.016 \\
\hline & $(0.005)$ & $(0.004)$ & $(0.003)$ & $(0.010)$ & $(0.003)$ & $(0.003)$ & $(0.003)$ & $(0.008)$ & $(0.005)$ & $(0.004)$ & $(0.003)$ & $(0.010)$ \\
\hline \multirow[t]{2}{*}{$(X-4) * 1[X \geq 4]$} & $-0.039 * *$ & & & & $-0.027 * *$ & & & & $-0.027 *$ & & & \\
\hline & $(0.017)$ & & & & $(0.012)$ & & & & $(0.016)$ & & & \\
\hline \multirow[t]{2}{*}{$(X-4.5) * 1[X \geq 4.5]$} & & $-0.058 * * *$ & & & & $-0.041 * * *$ & & & & $-0.040 * *$ & & \\
\hline & & $(0.022)$ & & & & $(0.015)$ & & & & $(0.019)$ & & \\
\hline \multirow[t]{2}{*}{$(X-5) * 1[X \geq 5]$} & & & $-0.093 * * *$ & & & & $-0.069 * * *$ & & & & $-0.068 * * *$ & \\
\hline & & & $(0.032)$ & & & & $(0.023)$ & & & & $(0.025)$ & \\
\hline \multirow[t]{2}{*}{$\mathrm{X}$-squared } & & & & $-0.004 * *$ & & & & $-0.003 * *$ & & & & -0.002 \\
\hline & & & & $(0.002)$ & & & & $(0.001)$ & & & & $(0.002)$ \\
\hline \multirow[t]{2}{*}{ Constant } & 0.004 & 0.006 & 0.009 & 0.003 & 0.001 & 0.002 & 0.003 & -0.002 & 0.005 & 0.006 & 0.008 & 0.004 \\
\hline & $(0.011)$ & $(0.010)$ & $(0.010)$ & $(0.011)$ & $(0.008)$ & $(0.008)$ & $(0.008)$ & $(0.009)$ & $(0.011)$ & $(0.010)$ & $(0.010)$ & $(0.011)$ \\
\hline Value of $X$ when $\Delta Y=0$ & 5.34 & 5.27 & 5.37 & 5.65 & 5.20 & 5.19 & 5.32 & 5.35 & 5.98 & 5.63 & 5.55 & 6.56 \\
\hline Individual FE & $x$ & $\times$ & $\times$ & $\times$ & $x$ & $\times$ & $\times$ & $x$ & $x$ & $x$ & $x$ & $\times$ \\
\hline Mean of $\Delta$ risk aversion & 0.018 & 0.018 & 0.018 & 0.018 & 0.018 & 0.018 & 0.018 & 0.018 & 0.020 & 0.020 & 0.020 & 0.020 \\
\hline Mean of risk aversion (before) & 0.738 & 0.738 & 0.738 & 0.738 & 0.738 & 0.738 & 0.738 & 0.738 & 0.736 & 0.736 & 0.736 & 0.736 \\
\hline $\mathrm{N}$ of individuals & 1,514 & 1,514 & 1,514 & 1,514 & 1,514 & 1,514 & 1,514 & 1,514 & 1,488 & 1,488 & 1,488 & 1,488 \\
\hline
\end{tabular}

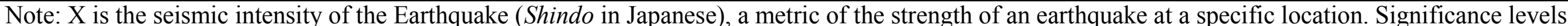

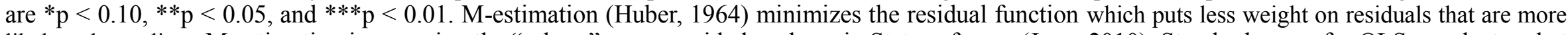

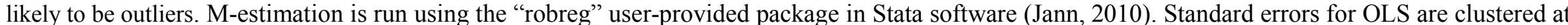

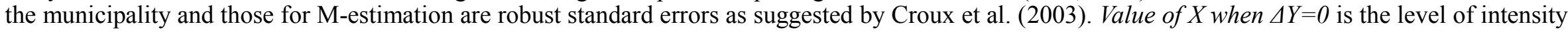
measure $(\mathrm{X})$ where change in risk aversion $(\Delta \mathrm{Y})$ switches signs. 
Table A6. Robustness Checks: Mean Reversion (Men Only)

Outcome: Risk Aversion Measure 1 (Transformed Price)

\begin{tabular}{|c|c|c|c|c|c|c|c|c|c|c|c|c|}
\hline & \multicolumn{12}{|c|}{ Men } \\
\hline & \multicolumn{4}{|c|}{ Baseline } & \multicolumn{4}{|c|}{$\begin{array}{l}\text { Excluding subjects with risk aversion } \\
\text { (category 9) } \\
\text { before the Earthquake }\end{array}$} & \multicolumn{4}{|c|}{$\begin{array}{l}\text { Excluding subjects with risk aversion } \\
\text { (categories } 8 \text { and 9) } \\
\text { before the Earthquake }\end{array}$} \\
\hline & (1) & $(2)$ & (3) & (4) & $(5)$ & (6) & $(7)$ & $(8)$ & (9) & $(10)$ & $(11)$ & $(12)$ \\
\hline \multirow[t]{2}{*}{$\mathrm{X}$} & $0.009 *$ & $0.007 *$ & 0.005 & $0.020 * *$ & 0.008 & 0.006 & 0.004 & $0.019^{*}$ & 0.009 & $0.008^{*}$ & 0.005 & $0.019 *$ \\
\hline & $(0.005)$ & $(0.004)$ & $(0.003)$ & $(0.010)$ & $(0.005)$ & $(0.004)$ & $(0.003)$ & $(0.011)$ & $(0.005)$ & $(0.004)$ & $(0.003)$ & $(0.011)$ \\
\hline \multirow[t]{2}{*}{$(X-4) * 1[X \geq 4]$} & $-0.039 * *$ & & & & $-0.039 * *$ & & & & $-0.039 *$ & & & \\
\hline & $(0.017)$ & & & & $(0.018)$ & & & & $(0.020)$ & & & \\
\hline \multirow[t]{2}{*}{$(X-4.5) * 1[X \geq 4.5]$} & & $-0.058 * * *$ & & & & $-0.059 * * *$ & & & & $-0.062 * *$ & & \\
\hline & & $(0.022)$ & & & & $(0.023)$ & & & & $(0.026)$ & & \\
\hline \multirow[t]{2}{*}{$(X-5) * 1[X \geq 5]$} & & & $-0.093 * * *$ & & & & $-0.098 * * *$ & & & & $-0.104 * * *$ & \\
\hline & & & $(0.032)$ & & & & $(0.033)$ & & & & $(0.039)$ & \\
\hline \multirow[t]{2}{*}{$\mathrm{X}$-squared } & & & & $-0.004 * *$ & & & & $-0.004^{*}$ & & & & $-0.003 *$ \\
\hline & & & & $(0.002)$ & & & & $(0.002)$ & & & & $(0.002)$ \\
\hline \multirow[t]{2}{*}{ Constant } & 0.004 & 0.006 & 0.009 & 0.003 & 0.012 & 0.013 & 0.016 & 0.010 & 0.018 & $0.019^{*}$ & $0.022 * *$ & 0.017 \\
\hline & $(0.011)$ & $(0.010)$ & $(0.010)$ & $(0.011)$ & $(0.011)$ & $(0.011)$ & $(0.010)$ & $(0.012)$ & $(0.012)$ & $(0.011)$ & $(0.011)$ & $(0.012)$ \\
\hline Value of $\mathrm{X}$ when $\Delta \mathrm{Y}=0$ & 5.34 & 5.27 & 5.37 & 5.65 & 5.40 & 5.30 & 5.38 & 5.69 & 5.74 & 5.47 & 5.47 & 6.21 \\
\hline Individual FE & $\times$ & $\times$ & $\times$ & $\times$ & $\times$ & $\times$ & $\times$ & $\times$ & $x$ & $\times$ & $\times$ & $\times$ \\
\hline Mean of $\Delta$ risk aversion & 0.018 & 0.018 & 0.018 & 0.018 & 0.022 & 0.022 & 0.022 & 0.022 & 0.030 & 0.030 & 0.030 & 0.030 \\
\hline Mean of risk aversion (before) & 0.738 & 0.738 & 0.738 & 0.738 & 0.727 & 0.727 & 0.727 & 0.727 & 0.706 & 0.706 & 0.706 & 0.706 \\
\hline No. of individuals & 1,514 & 1,514 & 1,514 & 1,514 & 1,455 & 1,455 & 1,455 & 1,455 & 1,343 & 1,343 & 1,343 & 1,343 \\
\hline R-squared & 0.004 & 0.004 & 0.005 & 0.002 & 0.003 & 0.005 & 0.005 & 0.002 & 0.003 & 0.005 & 0.006 & 0.002 \\
\hline
\end{tabular}

Note: $\mathrm{X}$ is the seismic intensity of the Earthquake (Shindo in Japanese), a metric of the strength of an earthquake at a specific location. Significance levels are ${ }^{*} \mathrm{p}<0.10,{ }^{* *} \mathrm{p}<0.05$, and ${ }^{* * *} \mathrm{p}<0.01$. Standard errors clustered at the municipality are reported in parentheses. Value of $X$ when $\Delta Y=0$ is the level of intensity measure $(X)$ where change in risk aversion $(\Delta Y)$ switches signs. 
Table A7. Robustness Checks: Alternative Measure of Risk Preference (Men Only) Outcome: Risk Aversion Measure 2 (Absolute Risk Aversion)

\begin{tabular}{lcccc}
\hline & \multicolumn{4}{c}{ Men } \\
\cline { 2 - 5 } & 0.012 & 0.010 & 0.005 & 0.025 \\
$\mathrm{X}$ & $(0.009)$ & $(0.008)$ & $(0.006)$ & $(0.019)$ \\
$(\mathrm{X}-4) * 1[\mathrm{X} \geq 4]$ & $-0.059^{*}$ & & & \\
& $(0.031)$ & & & \\
$(\mathrm{X}-4.5) * 1[\mathrm{X} \geq 4.5]$ & & $-0.096^{* *}$ & & \\
& & $(0.039)$ & & \\
$(\mathrm{X}-5) * 1[\mathrm{X} \geq 5]$ & & & $-0.146^{* * *}$ & \\
& & & $(0.055)$ & \\
$\mathrm{X}$-squared & & & & -0.005 \\
& & & & $(0.003)$ \\
Constant & 0.017 & 0.018 & 0.024 & 0.017 \\
& $(0.022)$ & $(0.021)$ & $(0.020)$ & $(0.023)$ \\
\hline Value of $X$ when $\triangle Y=0$ & 5.32 & 5.23 & 5.36 & 5.70 \\
Individual FE & $\times$ & $\times$ & $\times$ & $\times$ \\
Mean of $\Delta$ risk aversion & 0.031 & 0.031 & 0.031 & 0.031 \\
Mean of risk aversion (before) & 1.758 & 1.758 & 1.758 & 1.758 \\
No. of individuals & 1,514 & 1,514 & 1,514 & 1,514 \\
R-squared & 0.002 & 0.003 & 0.003 & 0.001 \\
\hline
\end{tabular}

Note: $\mathrm{X}$ is the seismic intensity of the Earthquake (Shindo in Japanese), a metric of the strength of an earthquake at a specific location. Significance levels are ${ }^{*} p<0.10,{ }^{* *} p<0.05$, and ${ }^{* * *} \mathrm{p}<0.01$. Standard errors clustered at the municipality are reported in parentheses. Value of $X$ when $\Delta Y=0$ is the level of intensity measure $(X)$ where change in risk aversion $(\Delta Y)$ switches signs. Note that the values of absolute risk aversion are multiplied by 1000 . 
Table A8. Robustness Checks: Changes in the Choice of Risk Aversion Category (Men Only)

Outcome: Ordinal Outcome of Risk Aversion Measure

\begin{tabular}{lcccc}
\hline & \multicolumn{4}{c}{ Men } \\
\cline { 2 - 5 } & $(1)$ & $(2)$ & $(3)$ & $(4)$ \\
\hline $\mathrm{X}$ & $0.036^{* *}$ & $0.030^{* *}$ & $0.021^{*}$ & $0.085^{* *}$ \\
$(\mathrm{X}-4) * 1[\mathrm{X} \geq 4]$ & $-0.018)$ & $(0.014)$ & $(0.011)$ & $(0.038)$ \\
& $(0.064)$ & & & \\
$(\mathrm{X}-4.5) * 1[\mathrm{X} \geq 4.5]$ & & $-0.213^{* *}$ & & \\
& & $(0.082)$ & & \\
$(\mathrm{X}-5) * 1[\mathrm{X} \geq 5]$ & & & $-0.375^{* * *}$ & \\
& & & $(0.129)$ & \\
$\mathrm{X}$-squared & & & & $-0.015^{* *}$ \\
& & & & $(0.007)$ \\
Constant & -0.012 & -0.006 & 0.003 & -0.024 \\
& $(0.039)$ & $(0.038)$ & $(0.036)$ & $(0.041)$ \\
\hline Value of X when $\Delta \mathrm{Y}=0$ & 5.19 & 5.19 & 5.31 & 5.36 \\
Individual FE & $\times$ & $\times$ & $\times$ & $\times$ \\
Mean of $\Delta$ risk aversion & 0.044 & 0.044 & 0.044 & 0.044 \\
Mean of risk aversion category (before) & 5.361 & 5.361 & 5.361 & 5.361 \\
No. of individuals & 1,514 & 1,514 & 1,514 & 1,514 \\
$\mathrm{R}$-squared & 0.004 & 0.005 & 0.006 & 0.003 \\
\hline
\end{tabular}

Note: Outcome is the ordinal outcome of risk aversion measure, which takes 1 if the person chose a higher risk aversion category after the Earthquake (i.e., is more risk averse) than that before the Earthquake; takes -1 if the person chose a lower risk aversion category after the Earthquake (i.e., is less risk averse) than that before the Earthquake; and 0 if the person chose the same category before and after the Earthquake. $\mathrm{X}$ is the seismic intensity of the Earthquake (Shindo in Japanese), a metric of the strength of an earthquake at a specific location. Significance levels are $* \mathrm{p}<0.10, * * \mathrm{p}<0.05$, and $* * * \mathrm{p}<0.01$. Standard errors clustered at the municipality are reported in parentheses. Value of $X$ when $\Delta Y=0$ is the level of intensity measure $(X)$ where change in risk aversion $(\Delta Y)$ switches signs. 


\section{Table A9. Alternative Measure of the Earthquake (Men Only)}

Outcome: Risk Preference Measure 1 (Transformed Price)

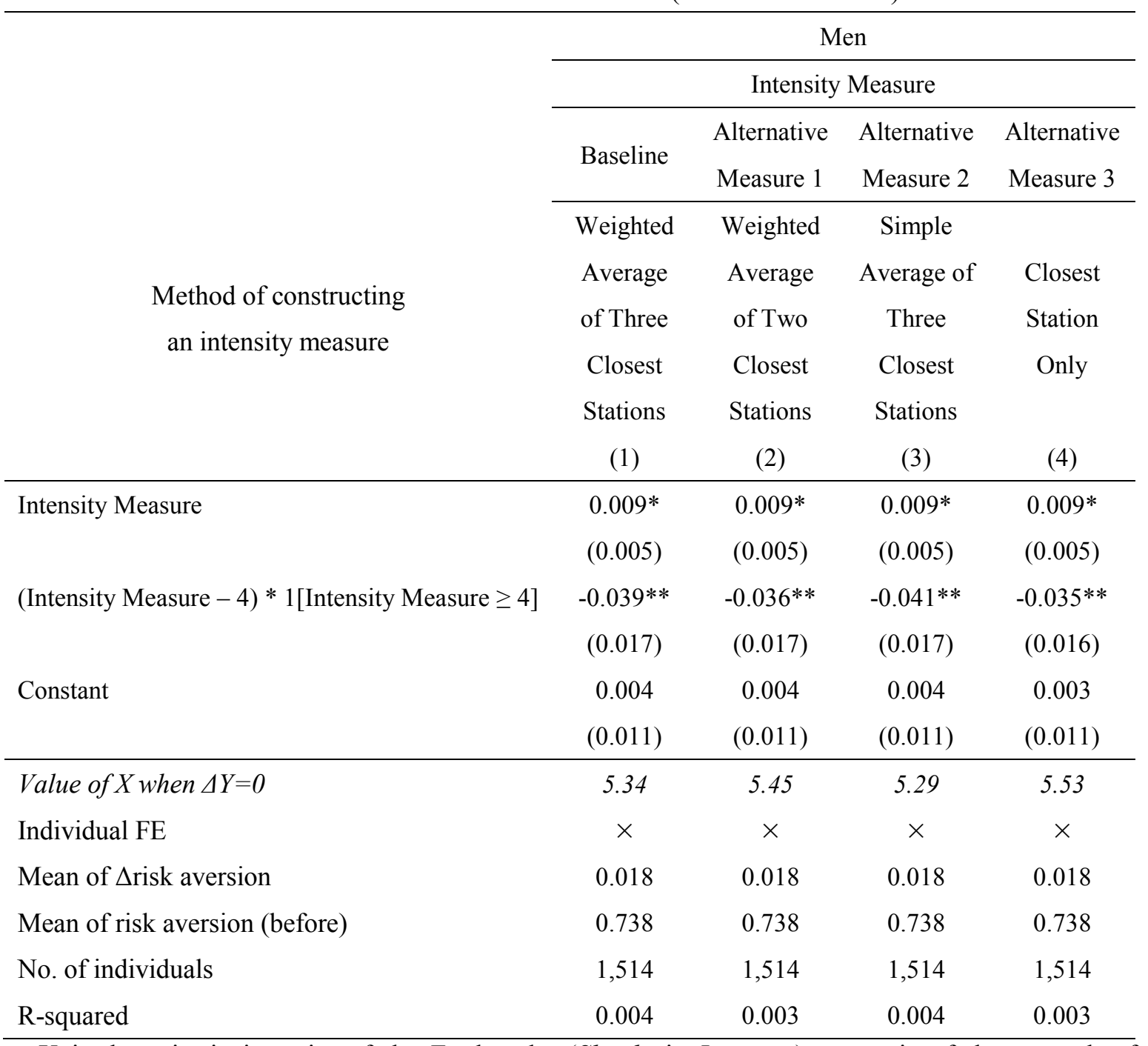

Note: $\mathrm{X}$ is the seismic intensity of the Earthquake (Shindo in Japanese), a metric of the strength of an earthquake at a specific location. Significance levels are $* p<0.10,{ }^{* *} p<0.05$, and $* * * p<0.01$. Standard errors clustered at the municipality are reported in parentheses. Weight is the inverse of the distance between the city hall and each monitoring station. Value of $X$ when $\Delta Y=0$ is the level of intensity measure $(X)$ where change in risk aversion $(\Delta Y)$ switches signs. 
Table A10. Results on Behavior (Women Only)

\begin{tabular}{lccc}
\hline \multirow{2}{*}{ Outcomes } & \multicolumn{3}{c}{ Women } \\
\cline { 2 - 4 } & Gambling & Drinking & Smoking \\
\hline $\mathrm{X}$ & $(1)$ & $(2)$ & $(3)$ \\
& -0.004 & 0.002 & -0.000 \\
$(\mathrm{X}-4) * 1[\mathrm{X} \geq 4]$ & $(0.004)$ & $(0.002)$ & $(0.000)$ \\
& 0.015 & 0.000 & 0.000 \\
Constant & $(0.014)$ & $(0.007)$ & $(0.000)$ \\
& 0.007 & -0.004 & 0.002 \\
Individual FE & $(0.009)$ & $(0.004)$ & $(0.002)$ \\
Income & $\times$ & $\times$ & $\times$ \\
Mean of $\triangle$ outcome & $\times$ & $\times$ & $\times$ \\
Mean of outcome (before) & -0.001 & 0.001 & 0.001 \\
No. of individuals & 0.040 & 0.005 & 0.002 \\
R-squared & 1,707 & 1,707 & 1,707 \\
X & 0.001 & 0.002 & 0.001
\end{tabular}

Note: $\mathrm{X}$ is the seismic intensity of the Earthquake (Shindo in Japanese), a metric of the strength of an earthquake at a specific location. Significance levels are $* p<0.10, * * p<0.05$, and $* * * p<0.01$. Standard errors clustered at the municipality are reported in parentheses. A gambling dummy takes one if the person is engaged in gambling once or more a week. A drinking dummy takes 1 if the person drinks 5 or more cans of beer $(12 \mathrm{oz}$. per can) or its equivalent a day almost every day. A smoking dummy takes 1 if the person smokes more than 30 cigarettes per day. Results for specifications with $(\mathrm{X}-4.5) * 1[\mathrm{X} \geq 4.5],(\mathrm{X}-5) * 1[\mathrm{X} \geq 5]$, and $\mathrm{X}$-squared are very similar (available upon request). 


\section{Table A11. Source of data and variable lists}

1. Intensity of the Earthquake

Detail: http://www.kyoshin.bosai.go.jp/kyoshin/quake/

Accessed: 12:32pm CST, Sep 13, 2013

Data on seismic intensity of the Earthquake is obtained from the Earthquake and Volcano Data Center, National Research Institute for Earth Science and Disaster Prevention (NIED), Japan. The Center maintains a strong-motion seismograph network (K-NET, Kik-net) that includes more than 1,700 observation stations distributed uniformly every $20 \mathrm{~km}$, covering Japan. The seismic intensity data as well as the geocode information of each observation station are collected for all major earthquakes in Japan.

2. Radiation

Detail: https://mapdb.jaea.go.jp/mapdb/portals/60/

Accessed: 3:55pm CST, March 11, 2014

Data on radiation are collected by the Airborne Monitoring Survey of the Ministry of Education, Culture, Sports, Science and Technology in Japan. The data were collected by airplane flight with altitudes between 150 and $300 \mathrm{~m}$. The flight paths had a width of at most $5 \mathrm{~km}$ and cover almost all municipalities in Japan. The air dose rate of radiation $(\mu \mathrm{Sv} / \mathrm{h})$ is adjusted to reflect the number at a height of $1 \mathrm{~m}$ above the ground. This is the only radiation survey that covered all municipalities across Japan after the Earthquake and accident at the Fukushima Daiichi Nuclear Power Plant. The survey was conducted between June 22, 2011 and May 31, 2012. Most of the affected municipalities were surveyed in 2011 while some of the less or almost non-affected areas, such as Hokkaido, Hyogo, Kyoto, Mie, Shiga, Shimane, and Tottori, are measured after March 2012.

3. Pre-Earthquake Hazard Prediction

Detail: http://www.j-shis.bosai.go.jp/download

Accessed: 12:54pm CST, March 12, 2014

This earthquake prediction is based on a 2010 report of the National Seismic Hazard Maps for Japan by the Headquarters for Earthquake Research Promotion of the Ministry of Education, Culture, Sports, Science and Technology, Japan. The report 
presents a detailed prediction on the probability of earthquake occurrence at a $250 \mathrm{~m}$ mesh code level. The prediction combines earthquake occurrence models, seismic source models, and subsurface structure models to calculate the predicted probability of different intensity levels at each mesh code level.

\section{Fatality Rate}

Detail: http://www.stat.go.jp/info/shinsai/zuhyou/data0422.xls

Accessed: 12:30pm CST, Sep 13, 2013

Fatality rate is created from the number of fatalities collected by the Fire and Disaster Management Agency (Shobo-cho, Saiagi Taisaku Honbu in Japanese) of the Ministry of Internal Affairs and Communications in Japan. The number is as of March 11, 2013, two years after the Earthquake. The numbers of deaths and missing people are reported at the municipality level for each affected municipality. We use the natural logarithm of one plus the numbers of deaths and missing people per million at the municipality level.

\section{Property value}

Detail: http://nlftp.mlit.go.jp/ksj/jpgis/datalist/KsjTmplt-L01-v1_1.html

Accessed: 11:28am, CST, June 26, 2014

Property value data are constructed by the Ministry of Land, Infrastructure, Transport and Tourism for the purpose of property tax evaluation based on the transaction price of nearby properties and other related factors. Property values as of January 1 for each year are published and the original data include more than 26,000 properties. We use the change of property values for the same property between 2011 and 2012 and take took a simple average of all properties located in each municipality. 